\title{
Predicting treatment completion: A study of the Federal Bureau of Prisons' Residential Drug Abuse Program
}

\author{
Y. Tami Yanez \\ West Virginia University
}

Follow this and additional works at: https://researchrepository.wvu.edu/etd

\section{Recommended Citation}

Yanez, Y. Tami, "Predicting treatment completion: A study of the Federal Bureau of Prisons' Residential Drug Abuse Program" (2005). Graduate Theses, Dissertations, and Problem Reports. 4205.

https://researchrepository.wvu.edu/etd/4205

This Dissertation is protected by copyright and/or related rights. It has been brought to you by the The Research Repository @ WVU with permission from the rights-holder(s). You are free to use this Dissertation in any way that is permitted by the copyright and related rights legislation that applies to your use. For other uses you must obtain permission from the rights-holder(s) directly, unless additional rights are indicated by a Creative Commons license in the record and/ or on the work itself. This Dissertation has been accepted for inclusion in WVU Graduate Theses, Dissertations, and Problem Reports collection by an authorized administrator of The Research Repository @ WVU.

For more information, please contact researchrepository@mail.wvu.edu. 
Predicting Treatment Completion:

A Study of the Federal Bureau of Prisons' Residential Drug Abuse Program

Y. Tami Yañez

\author{
Dissertation submitted to the \\ Eberly College of Arts and Sciences \\ at West Virginia University \\ in partial fulfillment of the requirements \\ for the degree of \\ Doctor of Philosophy \\ in \\ Psychology
William Fremouw, Ph.D., ABBP, Chair
Edward Baker, Ph.D.
Ryan Finkenbine, Ph.D.
Daniel McNeil, Ph.D.
Matthew Scullin, Ph.D. \\ Department of Psychology
}

Morgantown, West Virginia 2005

Keywords: Substance Abuse Treatment, Retention, Prisoners

Copyright 2005 Y. Tami Yañez 


\begin{abstract}
Predicting Treatment Completion:

A Study of the Federal Bureau of Prisons' Residential Drug Abuse Program
\end{abstract}

\title{
Y. Tami Yañez
}

Substance abuse and criminal behavior are two commonly associated social concerns. It is not surprising that substance abuse treatment also has demonstrated a reduction not only substance abuse, as well as criminal behavior. The Federal Bureau of Prisons' Residential Drug Abuse Program (RDAP) has demonstrated wide-reaching benefits. Understanding the $33 \%$ noncompletion rate of RDAP, then, is an important component of the treatment process. This study, therefore, sought to identify factors present prior to RDAP participation that may predict program completion, which may also guide efforts to reduce relapse and recidivism rates. RDAP completers were slightly more likely to have fewer adulthood incarcerations and significantly more likely to have longer duration of cannabis use. Non-completers were significantly more likely to have shorter current sentences and a trend towards having shorter duration of alcohol and amphetamine use. Elevated PAI Drug Problem scale and longer length of current sentence were found to help predict RDAP completion. The Psychological Inventory of Criminal Thinking Styles (PICTS) was not found to predict RDAP completion. Post-hoc analyses of early non-completers versus late non-completers found that early non-completers demonstrated more Cluster B characteristics than late non-completers. Future research should examine the heterogeneity of non-completers. 


\section{Acknowledgments}

I would like to express my gratitude to each member of my dissertation committee, past and present. To Lindsey Cohen and Stan Cohen, it was an honor to work with both of you and I wish you both the very best. Dan McNeil and Matt Scullin, I greatly appreciate your willingness to join this work in progress. To the remaining members of the original dream team, thank you for your guidance and encouragement throughout this research endeavor. Ryan Finkenbine, your contributions to this project fostered a successful multidisciplinary experience and I thank you. Ed Baker, my BOP sage, without your unwavering help and persistence, seeing this research project through to fruition would have been an unlikely possibility. Finally, to my mentor Bill Fremouw, my thanks are innumerable. I thank you for the vast academic and practical experiences you have afforded me, by taking me in as an orphan graduate student. I will forever be indebted to you for your wisdom and guidance.

Special appreciation goes to the Bureau of Prisons and the staff at FCI Morgantown who allowed for the completion of this research project. Thank you to my friend and colleague, Libby Tyner, for her much appreciated willingness to assist me with data collection.

To my beloved boyfriend, thank you for offering the much-needed comedic relief to the stresses of graduate school. I apologize if my stress sometimes dampened the comedy. To my sister and grandparents, as well as my extended family and friends, thank you for your emotional and spiritual support during my cross-country educational journey. It has been a comfort to feel your support, even when miles kept us apart.

To my inspirational parents, thank you for everything! With your support, guidance, and patience, I have come a long way from the shy little girl who refused to attend Winnie the Pooh daycare. I dedicate my educational successes to you both. The professional and spiritual examples set by you both have served as invaluable motivation to persevere through the challenges of graduate school, and will continue to guide me throughout the challenges of life. I love you. 
Table of Contents



Retention in Outpatient Programs................................................ 2

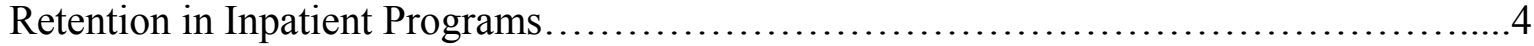

Retention in Corrections-based Programs...........................................4

Residential Drug Abuse Program and Relevant Research..............................5

Theories of Criminality...............................................................

Bureau of Prisons' Residential Drug Abuse Program .................................6

Retention in the Residential Drug Abuse Program.....................................8

Summary of Predictive Variables.......................................................9

Purpose........................................................................ 11

Design.......................................................................

Hypotheses................................................................

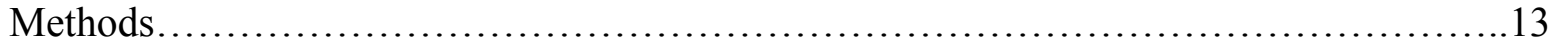

Research Setting............................................................... 13

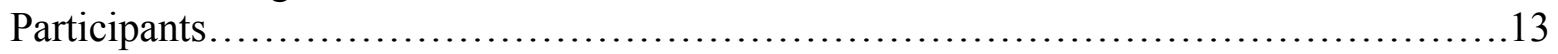

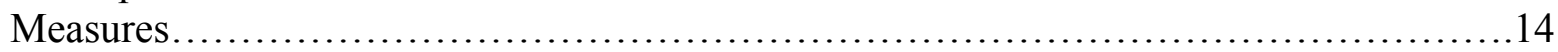

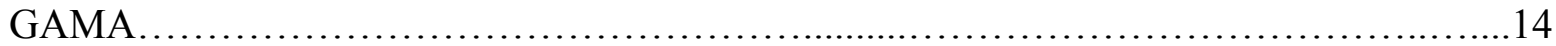

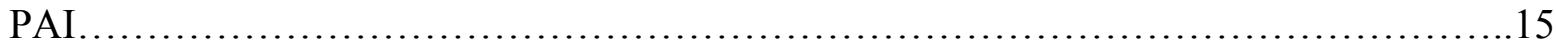



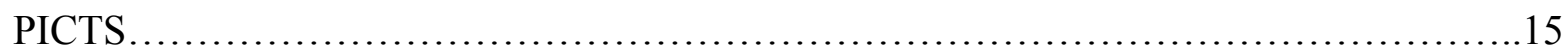

Review of Relevant........................................................... 16

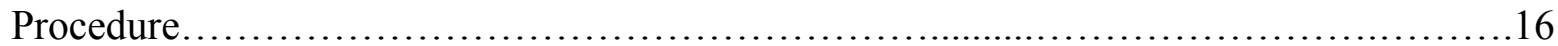

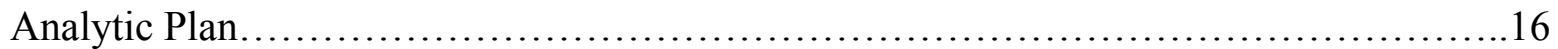

Univariate and Bivariate Analyses.............................................. 16

Multivariate Analyses.......................................................... 17

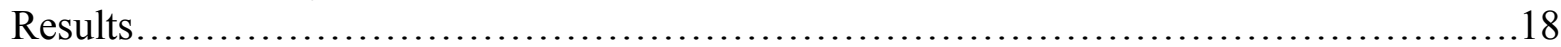

Intercorrelations.................................................................... 18

Analyses of Sociodemographic Variables........................................... 18

Analyses of Validity Scales..................................................... 19

Analyses of PAI Clinical and Treatment Scales ......................................20



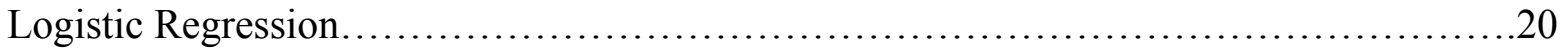

Discriminant Function Analysis.................................................... 21

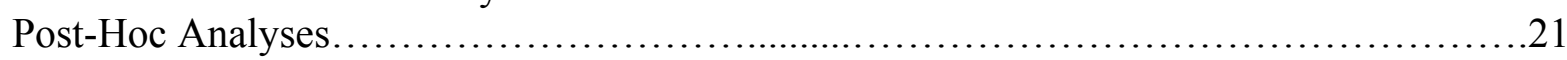



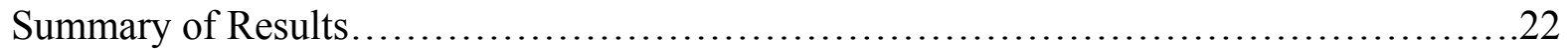

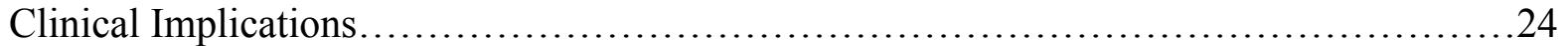

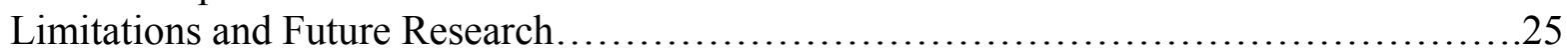

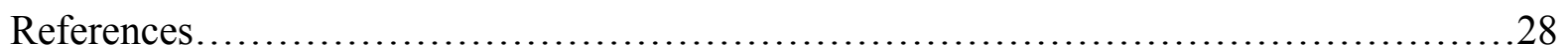

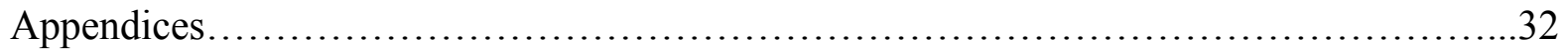

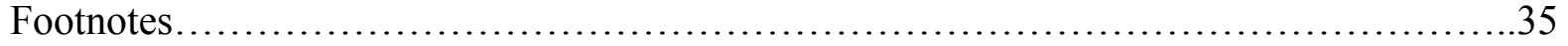




Predicting Program Completion:

A Study of the Federal Bureau of Prisons' Residential Drug Abuse Program

In 2002, an estimated 22-million Americans (9.4\% of the total population of individuals ages 12 and older) met diagnostic criteria for substance abuse or dependence (Substance Abuse and Mental Health Data Archives, n.d.). According to reports from the National Center on Addiction and Substance Abuse (CASA) in 1996, approximately 80\% (\$30-billion) of the correctional (e.g., jail, prison) expenditures \$38-billion budget was spent incarcerating individuals with substance-abuse histories or drug-related criminal behavior (as cited in McCollister \& French, 2002). Given the financial support afforded to substance-abuse programs, it is encouraging that client retention in such programs has consistently demonstrated benefits beyond decreased rates of relapse. In addition to lower rates of recidivism, completion of substance-abuse treatment programs has also been associated with improvements in psychological and physical health, as well as an increased rate of post-treatment employment (e.g., Bleiberg, Delvin, Croan, \& Briscoe, 1994; Condelli \& Hubbard, 1994; Leshner, 1997; McLellan, Luborsky, O’Brien, Woody, \& Druley, 1982; see Nielsen \& Scarpitti, 2002).

Although substance-abuse programs have demonstrated short- and long-term benefits of retention, drop-out rates range from 44\% to 89\% (Eisenberg \& Fabelo, 1996; Knight, Simpson, Chatham, \& Camacho, 1997; Ravndal \& Vaglum, 1991a) and, thusly, these people (noncompleters) do not experience the wide-ranging benefits of treatment. Therefore, reasons for non-completion of treatment have become an important research focus. Therapeutic approach (e.g., low intensity, therapeutic alliance) and personal characteristics of the treatment providers (e.g., race) has been reported to affect treatment completion (e.g., Kang, Kleinman, Woody, Millman, Todd, Kemp, \& Lipton, 1991; Kleinman, Moody, Todd, Millman, Kang, Kemp, \& Lipton, 1990). The substance abuser's motivation and preparedness to change has also been examined with regard to treatment completion (e.g., Hiller, Knight, Broome, \& Simpson, 1998). Pharmacotherapy has also been studied with regard to the prediction of medication compliance and treatment retention (Carroll, Rounsaville, \& Gawin, 1991; Gawin, Kleber, Byck, Rounsaville, Kasten, \& Jatlow, 1989). Additionally, methadone treatment programs have been evaluated to assess factors predictive of treatment completion (Saxon, Wells, Fleming, Jackson, \& Calsyn, 1996; Krebs, Brady, \& Laird, 2003).

Prospective studies of individual client characteristics, present at substance-abuse treatment intake, which predict program completion is the focus of this review. A study of methadone maintenance found treatment retention to be best predicted by older age, non-black race, lower Addiction Severity Index (ASI) legal composite scores, higher methadone dose level, and participation in programs that did not enforce contingencies for undesirable treatment-related behaviors (Saxon, Wells, Fleming, Jackson, \& Calsyn, 1996). Krebs, Brady, and Laird (2003) also reported that methadone use at jail admission was related to shorter treatment retention. It was theorized that this finding may have been a function of the relation between polysubstance abuse and poor treatment outcome (DeMaria, Sterling, \& Weinstein, 2000; Lamb, Kirby, \& Platt, 1996; Rowan-Szal, Chatham, \& Simpson, 2000).

Given that pharmacotherapy is not available for all substance addictions and that treatment programs tend to be composed of individuals addicted to various substances, studying 
the predictive factors of non-pharmacotherapy substance-abuse treatment programs may prove more generalizable to the field of substance-abuse treatment. Therefore, a review of research exploring the predictive factors of outpatient, inpatient, and corrections-based treatment program completion is warranted.

\section{Retention in Outpatient Programs}

White, Winn, and Young (1998) sought to "identify key predictors" of attrition from an intensive outpatient substance-abuse program. Individuals meeting the study's inclusion criteria (i.e., alcohol and/or drug abuse, privately insured or ability to self-pay) participated in approximately four weeks of programming, with four to thirteen contact hours per week with a counselor. The program primarily utilized a cognitive/behavioral-based treatment approach. A "comprehensive intake/assessment package" was administered to participants, however, only data from the Addiction Severity Index (ASI) was analyzed in this study, along with basic demographic data and family member attendance at family group sessions. Program completers ranged in stay from 10 to 64 days, dependant upon extraneous variables (e.g., medical illness) necessitating that participants leave treatment and then return at a later time.

Initial discriminant function analyses demonstrated that ASI composite scores and severity ratings were not useful predictors of program completion. A subsequent discriminant function analysis examined eight ASI items, as well as family involvement in treatment. Results suggest that Hispanic ethnicity, absence of a professional skill, shorter time since last hospitalization, cocaine or cannabis use in the last 30 days, higher number of family members with drug problems, presence of emotional abuse in last 30 days, concern with family problems, and low number of family group meetings attended by family members are predictive of poor program retention (White et al., 1998).

The Treating Cocaine Abuse (TCA) project was a comparative study of an another cognitive-behavioral relapse-prevention program and a recovery support group based on the Twelve Steps of Alcoholics Anonymous were the focus of the comparative Treating Cocaine Abuse (TCA) project. The first 14 sessions of both programs took place over a 12-week period. At 4-week intervals, participants in both programs attended three review sessions, totaling 17 sessions over a 24-week period. Since results of the initial unpublished study demonstrated there were no significant differences in program efficacy or participant demographics, Gainey, Wells, Hawkins, and Catalano (1993) combined data obtained from both programs to examine factors related to treatment retention among 110 male and female cocaine users in outpatient treatment. Treatment retention was operationally defined as attendance of at least eight of the 17 sessions offered. Predictor variables were organized into four main categories: (1) social isolation, stability, and support, (2) extent of involvement in a drug-using lifestyle, (3) motivation, and (4) demographics. All predictor variables were entered into a single logistic regression, controlling for all other variables. The model was then reduced, and only those predictor variables which were significant at the bivariate or multivariate levels were entered into the equation. A stepwise logistic regression resulted in the final predictive model. The resultant predictive factors of living alone, prior polysubstance use, length of cocaine use, and external motivation were examined. Results of this study indicated that "drop-outs" tended to have used cocaine for a shorter period of time and have had a more limited social support network. Finally, "drop-outs" tended to have 
reported participating in, or have historically been arrested for, more illegal activities prior to treatment, with the majority reporting drug-distribution activity (Gainey et al., 1993).

Predictive factors of completion of a program utilizing the Minnesota Model (i.e., intensive outpatient treatment) were explored by Veach, Remley, Kippers, \& Sorg (2000). The hospital-based program included either 16 or 30 hours of client contact per week (dependent upon level of program intensity), with study participants remaining in treatment from one day to over 30 days. The following termination statuses were considered as retained in treatment (completed treatment): continuing care, completed treatment, inpatient, another level of care with the facility, transferred, and referred out. The following termination statuses were considered dropouts: administrative discharge, against staff advice, cancelled, no show, and refused admission.

The following factors were explored for a relation with treatment retention: gender, age, employment status, number of problems on treatment plan, DWI related referral, and primary DSM-IV substance related diagnosis. Data was collected, ex-post facto, from 509 adult males and females who participated in the program over an 18-month period. Utilizing descriptive statistics, Wilks Lamda, and univariate $F$ ratios, treatment completers were found to have had significantly more treatment-plan problems, were more likely have a diagnosis of alcohol abuse, were less likely to have a diagnosis of cocaine abuse, and were more likely to be employed during the course of treatment (Veach et al., 2000).

McCaul, Svikis, and Moore (2001) examined predictors of program participation and longer retention for 268 patients treated at an urban, hospital-based outpatient substance-abuse treatment clinic. Using a multiple regression analysis, substance abuse was not found to predict program participation or retention. Rather, clients were more likely to attend more sessions if they were Caucasian, male, and had a high pre-treatment employment composite score on the ASI.

Prediction of program completion was also examined in a hierarchical therapeutic community of 144 substance abusers in Norway (Ravndal 1991a, 1991b; Ravndal and Vaglum, 1994). The program consisted of a one-year inpatient component described as "intensive, highly confrontational, [and] group-oriented." Following the completion of the inpatient component, subjects participated in six months of outpatient treatment consisting of one group meeting each week, working as a junior staff in the program (first three months), and regular outside employment (last 3 months). At intake, clients were briefly interviewed by staff, administered a structured research interview (e.g., sociodemographic data, family background, education, employment, substance abuse, legal problems, social adjustment, prior treatment, prostitution and sexual assaults), and completed three self-report instruments: Million Clinical Multiaxial Inventory (MCMI), Basic Character Inventory, and Symptom Checklist-90. All substance abuse was measured as frequency of use during the six months prior to program entry. Only twentynine clients $(20 \%)$ of the original client sample completed 18 months of the treatment program.

Ravndal (1991b) examined the role of antisocial aggressiveness in predicting completion of this program. Clients with higher intake scores on the MCMI antisocial aggression scale demonstrated no significant changes in scores over the course of treatment, but had a higher rate 
of non-completion (45\%) of the out-patient component of the program than did clients with lower MCMI antisocial aggressions scores that increased over the course of treatment.

Ravndal (1994) also examined the predictive power of depression with regard to program completion in the same hierarchical 1-year inpatient/6-month outpatient therapeutic community. In addition to the same subject pool and methods of data collection utilized in the previous study were employed, data from 36 drug-free clients were included. Utilizing a logistic regression, it was found that depression did not predict non-completion of the inpatient phase of treatment. Depression did emerge as a predictive factor after one year of treatment, however, depressed clients were five time more likely to drop out of the out-patient treatment program.

\section{Retention in Inpatient Programs}

Ravndal (1991a) also examined the predictive power of psychopathology and substance abuse with regard to completion of the in-patient phase of the 18-month program. Forty-three $(30 \%)$ of the original 144 subjects completed the inpatient component of the program. A logistic regression was utilized to examine predictive power of amphetamine use, alcohol use, gender, and psychopathology with regard to inpatient and total program completion. Ravndal and Vaglum (1991a) report pre-admission use of alcohol and amphetamine were the most powerful predictors of inpatient treatment completion. Completion of the 18-month total program was best predicted by gender (female), higher frequency of histrionic traits, and a lower frequency of schizotypal traits, as compared to non-completers.

Predictors of residential program completion among pregnant women, or women who entered treatment with their children were examined by Knight, Logan, and Simpson (2001). The Salvation Army's First Choice Program (First Choice) is a 12-month residential program for women with dependent children. The Initial Self-Rating Form and an extensive 90-minute intake interview were completed prior to the beginning treatment. Specifically, data was collected on sociodemographic variables, substance use, legal involvement, psychological functioning, and social relations. At discharge, completion status was determined based on sufficient length of stay (i.e., 6 months), personal progress toward treatment goals, and being in good standing with the agency. Utilizing a multivariate prediction model, women who completed program requirements were more likely to have at least a high school diploma or GED, no arrests in the six months prior to admission, and reported having fewer socially deviant peers. Additionally, the authors note that marital status, number of dependent children, child welfare involvement, cocaine use, and depression, while not statistically significant predictors, demonstrated a strong relation to program completion (Knight et al.).

\section{Retention in Corrections-Based Programs}

Substance-abuse treatment within correctional settings has historically received limited empirical attention (Leukefeld, Matthews, \& Clayton, 1992). One reason for the limited study of program retention among prisoners may be a misconception that inmate participation in corrections-based treatment programs is mandatory and completion of the program is strictly enforced. Often times, however, it is only recommended, and not required, that prisoners participate in corrections-based programming. Different types of reinforcements are incentives to 
participate (e.g., early release), but ultimately the prisoner decides what type and intensity of programming he or she will complete.

A recent study by Nielsen and Scarpitti (2002) improved this research area by simultaneously examining different types of predictive factors of program completion. Data from the first five years of CREST Outreach Center's operation was examined. CREST is a residential community-based therapeutic community lasting approximately six months for prison inmates with histories of substance abuse.

Nielsen and Scarpitti (2002) examined seven categories of independent variables. First, demographic/background factors included gender, race, education, age, marital status, and number of children. Second, criminal history included whether an inmate's instant offense was a property offense, a violent offense, or a drug-related offense, or "other," and at what age the inmate was first arrested. Third, prior substance abuse was measured by frequency of marijuana use, cocaine use, and crack use. Additionally, the presence of a history of heroin use was included. Fourth, a history of substance-abuse treatment was recorded for each inmate. Fifth, motivation and readiness were examined by whether or not the inmate considered him/herself an "addict," and an inmate's "drug-use plans for the next year". Sixth, psychological factors (i.e., obsession-compulsion, depression, anxiety, interpersonal sensitivity, paranoid ideation, hostility, and self-esteem) were assessed using the Revised Symptom Checklist-90 (SCL-90R; Derogatis, 1977). Finally, an inmate's legal pressures to attend treatment were examined. They utilized two dependent variables: completion and days in treatment. Completion was operationally defined as whether the client addressed major treatment issues, modeled appropriate behavior and attitude, and obtained employment. Non-completion of the program was determined by a voluntary return to prison in lieu of continuing CREST, or those who returned to prison as a result of expulsion from CREST for severe rule violations.

Utilizing a logistic regression analysis and an ordinary least squares regression, the simple variable of "frequent marijuana use prior to treatment" best predicted program completion and days in treatment, respectively. When examining only program completion, inmates with higher levels of education and higher levels of obsession-compulsion were more likely to complete CREST.

Residential Drug Abuse Program and Relevant Research

\section{Theories of Criminality}

Understanding criminal behavior has been the focus of sociological theorists for many years. The ecological perspective of criminality (also termed Chicago school) contains three primary theories (Whitehead \& Lab, 1999). The concentric zones theory and delinquency areas theory posit that geographic factors contribute to criminality. The social areas theory, however, suggests that social characteristics of individuals concentrated in an area create an environment susceptible to crime. The sociological learning perspective of criminality examines the role of social learning as it relates to criminality (Whitehead \& Lab). For example, Sutherland's differential association theory simply posits that individuals learn from direct social contact with others; therefore, contact with deviant peers results in deviant behavior by the target individual, 
whereas others suggest that deviant social learning can also take place via indirect contact (e.g., media). Additionally, a process of operant condition takes place when individuals witness favorable outcomes for other individuals engaging in deviant behavior. The subculture explanations of criminality explore the effect of social status and social group norms with regard to criminal behavior (Whitehead \& Lab). Conversely, sociologists such as Durkheim and Merton offer social control theories to examine the inhibiting effects of social factors with regarding to criminal behavior. Social structure is also the focus strain theory. Specifically, it is theories that that anomie, or normlessness, causes social chaos resulting in individual means and goals incongruence (Whitehead \& Lab, 1999).

The lifestyle model of criminal conduct (Walters \& White, 1989) theorizes that criminal behavior results from the interaction of three primary factors termed the "three Cs". First, conditions include internal (e.g., heredity, intelligence), external (e.g., family, peers), and interactive (e.g., person $\mathrm{x}$ situations) components which may expand or inhibit a person's life options. Individuals then have the opportunity to make a choice of the available life options. As a result of various choices made, the individual may then come to alter their cognitions to decrease potential cognitive dissonance which may arise. It is further theorized that the "three Cs" merge over time, to create a dynamic and multidirectional system of interacting behavioral influences that retains the role of individual differences. It is this lifestyle model of criminal conduct that the Federal Bureau of Prisons' Residential Drug Abuse Program is based upon.

\section{Bureau of Prisons’ Residential Drug Abuse Program}

Established in 1990, the Residential Drug Abuse Program (RDAP) focuses not only on substance abuse, but on the criminal lifestyle as well. RDAP is currently in operation in 42 Bureau of Prison (BOP) institutions, including Federal Prison Camps, Federal Correctional Institutions, and Federal Medical Centers. This three-phase voluntary treatment program was designed with the end goal of reducing both post-release relapse and recidivism. All RDAP participants must satisfy four eligibility criteria: (1) he/she meets DSM-IV diagnostic criteria for alcohol or illegal/illicit drug use or dependence disorder and a records review supports this diagnosis, (2) he/she has no serious mental impairment that would substantially interfere with or preclude full program participation, (3) he/she signs the agreement to participate in RDAP, (4) generally, he/she is within 36 months from release from the BOP.

Participation in this program may be voluntary or court recommended. Inmates participating in the intensive residential treatment (Phase One) of RDAP are assigned to the treatment-designated housing unit at the institution. Participants are then organized into groups of approximately 30 inmates with similar projected release dates. Participation in RDAP consists of structured group treatment or activities for approximately 3 hours each day, five days each week, for 6-, 9-, or 12-months (i.e., ranging from 300 to 700 hours in treatment). While the length of programs may vary across institutions, a standard treatment package is consistent across RDAP sites in accordance with BOP policy.

Phase One was established upon the premises that the inmates are responsible for their behaviors and they are able to change those behaviors. In accordance with these premises, Phase One consists of five general skill-building approaches. First, Rational-Emotive/Rational- 
Behavior Therapy is designed to teach inmates to distinguish rational from irrational beliefs. Further, inmates are encouraged to understand the impact of personal beliefs on their behavior.

Second, Errors in Thinking focuses on reframing eight common criminal thinking errors, as adapted from Yokelson and Samanow's 52 thinking errors (1986) and related to the cognitive component of the lifestyle model of criminal conduct. The first of the eight errors, mollification, is the thinking style utilized when a criminal justifies and rationalizes his or her norm-violating behavior by focusing on social injustice, minimizes the seriousness of specific antisocial acts, or projects blame onto the victims of his or her crimes. The second thinking error, cutoff, is characterized by a quick elimination of fear, anxiety, and other psychological deterrents to criminal behavior. Entitlement, the third thinking error, takes place when the criminal displays a misconception of ownership, privilege, and lacks the ability to distinguish between "needs" and "wants". Fourth, the thinking error of power orientation is when the individual engages in outward displays of aggression in a self-serving attempt to control or manipulate others. Fifth, the thinking error of sentimentality is characterized by performing seemingly selfless good deeds in a purposeful and premeditated attempt to seek forgiveness for past criminal behaviors. Superoptimism, the sixth thinking error, is the criminal's tendency to overestimate chances of avoiding negative consequences of criminal behaviors. "Lazy thinking, short-cut problem solving, and uncritical acceptance of personal ideas and plans" characterize the seventh criminal thinking error of cognitive indolence (Walters, 1995, p. 309). Finally, the discontinuity style of thinking suggests minimal premeditation in cognitions, resulting in a tendency not to follow through on initially good intentions. Additionally, RDAP participants are encouraged to develop honesty, tolerance, respect, and responsibility.

Third, Communication and Interpersonal Relationships Skill-Building consists of lessons intended to improve communication skills, family relationships, and emotions. Specifically, inmates are instructed in appropriate assertiveness skills, empathy, coping with emotions, and the relation between their own childhood experiences and their past and future parenting skills. Fourth, Relapse Prevention and Wellness consists of the development of individual relapseprevention plans, including the effectiveness of physical exercise, to be utilized while at the institution and after release. Finally, Release Planning teaches concrete community-living skills such as securing employment, housing, and medical attention. Additionally, coping with issues related to re-entering society as a felon are addressed.

Successful completion of RDAP may result in as much as one-year decrease in time incarcerated, dependant upon individual qualification (e.g., non-violent offense, absence of a weapon during commission of instant offense). While the institution-based Phase One of RDAP is the focus of the proposed project, it should also be noted that, following the completion of the intensive residential treatment program, inmates participate in the Transitional Services portion (Phase Two) of the program. During Phase Two, inmates are required to attend one meeting per month, for up to 12-months, at the institution prior to their release. Finally, the Community Aftercare portion (Phase Three) lasts for a maximum of 6-months, consisting of outpatient, community-based drug abuse treatment at a half-way house near the offender's home community. 
Over the past 20 years, the United States federal prison population has rapidly increased with approximately $68 \%$ of the increase accounted for by drug-law violators (McCollister \& French, 2002). In 1997, an estimated $50 \%$ of all federal inmates reported using drugs in the month prior to committing their offense (Bureau of Justice Statistics (BJS), 1999), and up to 80\% of inmates admit to drug use in their lifetime (BJS; National Center on Addiction and Substance Abuse (CASA), 1998). Currently, 53.8\% of the 182,101 federal prison population of men and women are convicted of drug-related offenses (Federal Bureau of Prisons, 2005).

Given the increase in the number of inmates with documented drug-related problems, participation in the Drug Abuse Program (DAP) within the BOP has also steadily increased, with more than 10,000 inmates nationwide currently participating in RDAP. Additionally, Langan and Pelissier (2001) reported graduates of the Federal Bureau of Prisons' substance abuse treatment programs are $74 \%$ less likely to engage in misconduct over a 14-month post-treatment period of incarceration.

Information released by the BOP and National Institute on Drug Abuse in 1998, shows completion of RDAP significantly decreases criminal behavior in ex-inmates. Specifically, as compared to released inmates who did not participate in RDAP, six months following release, RDAP completers are $73 \%$ less likely to be re-arrested and $44 \%$ less likely to resume drug use. Further, the Office of National Drug Control Policy reports a recidivism rate of 3.3\% within six months after release from prison for inmates completing RDAP, as compared to $12.1 \%$ for nontreated inmates (as cited in McCollister \& French, 2002).

\section{Retention in the Residential Drug Abuse Program}

The BOP initiated an empirical investigation of the drug-abuse treatment provision within the BOP and its efficacy. The Treating Inmates Addicted to Drugs (TRIAD) study is a three-year outcome design of male and female inmates within the BOP (Pelissier, 2000). Treatment entry and completion was one focus of the TRIAD study. Researchers collected background information and administered the Change Assessment Scale, DSM-III-R automated Diagnostic Interview Schedule for depression and antisocial personality disorder, and Hope Scale to inmates who were eligible for treatment but did not enter, those who entered treatment but did not complete the program ( 802 men, 292 women), and those who completed treatment (932 men 193 women). For males and females, treatment completion was positively associated with current offenses of greater severity, no lifetime diagnosis of depression or Antisocial Personality Disorder (ASP), and higher maintenance factor scores of the Change Assessment Scale. Also, for both males and females, treatment completion and was less common among those with higher precontemplation factor scores at pre-treatment. Furthermore, for men, treatment completion was positively associated with older age at current commitment, plans to live with children who are minors after release, and higher contemplation scores. Also, for men, treatment completion was negatively related to a recent history of a violent offense, longer sentence lengths, average or good family ties, prior drug treatment, and not benefiting from the sentence-reduction provision.

Pelissier, Camp, and Motivans (2002), utilizing a sub-sample (1,446 male and female inmates) of the TRIAD sample, examined predictive factors of treatment retention in twenty 
BOP RDAPs. Researchers conducted individual background interviews to collect information on basic demographic data, history of violence, and substance-abuse history. Additionally, the DSM-III-R Diagnostic Interview Schedule (DIS) modules for ASP and depression were administered. Finally, motivation was measured via the Change Assessment Inventory and whether the inmate would benefit from the sentence-reduction provision. Disciplinary discharges were found to be more common among younger inmates, those with a history of violence, and those with a lifetime diagnosis of ASP. RDAP non-completion due to the inmate's withdrawal from the program was less common among men and those individuals with higher levels of motivation for change. Pelissier and colleagues recommended that the results of this study may support the denial of acceptance into RDAP where treatment resources are limited until the "individual meets a minimal threshold".

In a related BOP report, Pelissier (in press) examined 1,489 RDAP participants and 740 non-treatment (comparison) participants. The following data was collected for each inmate: demographic, criminal history, employment status, family background, substance-abuse history, and eligibility to benefit from the sentence-reduction provision. Additionally, all inmates were administered the DSM-III-R DIS modules for ASP and depression, the Change Assessment Scale, Hope Scale, and Ways of Coping Questionnaire. Race and ethnicity were not related to treatment entry or retention. Among males and females, treatment completion was found to be positively related to greater severity of current offense and no lifetime diagnosis of ASP. For males, older age, stronger family ties, and plans to live with children who are minors upon release were positively related to treatment completion. A recent history of perpetrating violence, longer sentences, prior drug-abuse treatment, and ineligibility to benefit from the sentencereduction provision were negatively associated with treatment completion among men. Several factors of the Change Assessment Scale were also found to be related to treatment completion. Specifically, men and women with higher precontemplation scores were less likely to complete treatment, while those with higher maintenance scores were more likely to complete treatment. Finally, men with higher contemplation scores were more likely to complete treatment.

$$
\text { Summary of Predictive Variables }
$$

\section{Demographic Variables}

Demographic variables historically found to predict program retention may be divided into five categories: age, race/ethnicity, education, substance abuse (i.e., abuse history and treatment history) and criminal history.

Age. First, replication of the predictive power of age has been demonstrated in several retention studies of outpatient, inpatient, and corrections-based treatment programs. The relation between age and retention, however, has shown mixed results. For example, some researchers have demonstrated younger participants fair better in treatment programs (Gainey, Wells, Hawkins, \& Catalano, 1993). One reason may be that younger individuals may have a shorter history of risky behavior and, thus, more amenable to change. Others, however, report that older participants are more likely to complete treatment programs (Krebs, Brady, \& Laird, 2003; Saxon, Wells, Fleming, Jackson, \& Calsyn, 1996; Pelissier, 2000; Pelissier, Camp, \& Motivans, 2002; Pelisser, in press). This finding may suggest that their history of substance-abuse-related 
negative experiences may serve to convince the individual that treatment is necessary at this time in order to prevent future difficulty (e.g., physical ailments, legal problems, family problems).

Race/Ethnicity. The impact of an individual's ethnicity on program completion has also produced mixed empirical data. Pelissier (in press) found no association between race/ethnicity and program completion. Others, however, have demonstrated a negative relationship between non-white clients and program completion (White et al., 1998; Saxon, Wells, Fleming, Jackson, \& Calsyn, 1996).

Education. Third, educational level has been shown to predict program completion. Specifically, individuals with at least a high school diploma or GED (Knight et al., 2001; Nielsen \& Scarpitti, 2002) appear to do better in substance-abuse treatment programs, while the absence of a professional skill appears to negatively affect program completion (White et al., 1998). A related factor, participant intelligence, has not been examined as a predictive factor of program completion.

\section{Substance Abuse History}

Abuse History. An individual's history of substance abuse may be described in two categories. First, an individual's abuse or dependence of specific substances has demonstrated predictive power of program retention. Specifically, higher rates of program retention have been associated with a primary diagnosis of alcohol abuse or dependence (Veach, Remley, Kippers, \& Sorg, 2000; Ravndal \& Vaglum, 1991a), amphetamine abuse or dependence (Ravndal \& Vaglum, 1991a), and cannabis abuse or dependence (White et al., 1998; Nielsen \& Scarpitti, 2002). The evidence of the predictive power of cocaine abuse or dependence is conflicting. Some have demonstrated that cocaine abuse or dependence is predictive of program completion (White et al., 1998; Knight et al., 2001), while others report individuals addicted to cocaine were less likely to complete substance-abuse treatment programs (Veach, Remley, Kippers, \& Sorg, 2000).

The second category under history of substance abuse is the severity or duration of abuse. Completion of outpatient cocaine-abuse treatment was found to be negatively affected by a less extensive history of cocaine abuse (Gainey et al., 1993). As with age, a possible explanation for this finding may be that individuals with longer histories of abuse may have experienced greater drug-related personal difficulties and may have attempted treatment programs/recovery more times in the past. Additionally, individuals with generally more severe substance-abuse problems (e.g., polysubstance abuse, length of abuse) tend to have greater difficulty completing substanceabuse treatment programs (e.g., Wickizer, Maynard, Atherly, Fredrick, Koepsell, Krupski, \& Stark, 1994).

Treatment History. Prior treatment history has consistently been negatively associated with current program completion (e.g., Pelissier, 2000; Pelissier, in press). It is likely, however, that having participated in prior treatment programs does not render an individual less apt to complete future programs. Rather, it appears more likely that relapse after participation in prior treatment programs, resulting in the need for the current treatment program, decreases an individual's chance at completing the current program. 


\section{Criminal History}

An individual's criminal history has consistently been negatively associated with program completion. A more extensive criminal history (Gainey et al., 1993), history of violent offenses, severity of current offense, and longer current sentence are negatively associated with program completion (Pelissier, 2000; Pelissier, Camp, Motivans, 2002; Pelissier, in press). It is suggested that a more sustained criminal lifestyle may be accompanied by a variety of intraindividual and interpersonal expectations that may hinder an individual's ability or motivation to complete substance abuse treatment.

Psychological Factors

The relationship between psychological problems and completion of treatment has been the focus of several retention studies. Program completion has been positively associated with a higher frequency of histrionic personality characteristics (Ravndal \& Vaglum, 1991a) and obsessive-compulsive tendencies (Nielsen \& Scarpitti, 2002). Lower levels of schizotypal characteristics have also been associated with treatment retention (Ravndal \& Vaglum, 1991a). Depressed clients, however, have demonstrated significant difficulty in the completion of substance-abuse treatment (Ravndal, 1994; Knight et al., 2001). Poor treatment retention has also been associated with higher levels of antisocial aggression (Ravndal, 1991b) and a diagnosis of Antisocial Personality Disorder (Pelisser, 2000; Pelissier, Camp, \& Motivans, 2002; Pelissier, in press).

A related aspect of criminality that has not been explored is a cognitive component. Theoretically associated with criminal behavior, as described by Yokelson and Samenow (1974, 1986), individuals demonstrate a network of thinking styles and/or errors that are theorized to categorize individuals on a continuum of responsibility. On this continuum, the "severe criminal" takes the least responsibility for the behavioral effects of his or her maladaptive cognitions. Thus, criminal thinking styles are associated with more extensive criminal behavior (Yokelson \& Samenow, 1974, 1986). Further, extensive criminal behavior has been associated with higher drop-out rates (Gainey et al., 1993; Knight et al., 2001). Therefore, one may extrapolate that criminal thinking styles may be associated with drop-out rates as well.

\section{Purpose}

The purpose of the proposed project, then, is multi-faceted. This project increases the understanding of individual factors that are indicative of a poor probability of completing RDAP. Guided by this information, treatment planning may be tailored to target specific aspects of an individual's clinical presentation, while retaining the structure of RDAP. As a result, the current Phase One RDAP completion rate of 67\% at FCI Morgantown (Baker \& Koch, personal communication, September 28, 2003) may increase. It would follow that subsequent decreases in relapse and recidivism rates may occur amongst RDAP completers from FCI Morgantown. Further, understanding factors associated with RDAP completion at FCI Morgantown will likely benefit BOP RDAPs nationwide. 


\section{Design}

This is a two-group design study of predictive factors of program completion. Pretreatment data obtained from members of both groups, completers and non-completers, were analyzed to explore predictive ability.

Hypotheses

The following hypotheses are primarily based on the available literature of prediction of substance abuse program retention/completion. Hypotheses are organized by type of variable: demographic, substance use history, criminal history, psychological/cognitive styles.

\section{Univariate Prediction}

Hypothesis One. It is hypothesized that older age, higher IQ, and higher level of education will be positively associated with program completion.

Hypothesis Two. It is hypothesized that a longer history of cocaine, heroin, and alcohol abuse will be positively associated with program completion. A shorter history of marijuana is hypothesized to be negatively associated to program completion.

Hypothesis Three. It is hypothesized that number of incarcerations will demonstrate a positive relationship to program completion, while history of violent offenses will be negatively associated with program completion.

Hypothesis Four. It is hypothesized that depressed mood, antisocial characteristics, and schizotypal symptoms (as measure by the PAI) will be negatively associated with program completion.

Hypothesis Five. It is hypothesized that the PICTS criminal thinking styles of mollification, entitlement, and superoptimism will be negatively associated with program completion.

\section{Multivariate Prediction}

Hypothesis Sixe. It is hypothesized that older age, more extensive substance abuse and criminal histories, and the criminal thinking styles of entitlement and mollification will emerge as significant predictors of program completion.

Hypothesis Seven. It is hypothesized that significant predictive factors will correctly classify program completers versus non-completers beyond the probability of chance. 
Methods

\section{Research Setting}

The Federal Correctional Institution in Morgantown, WV (FCI Morgantown) is a minimum-security male correctional facility. Inmates who have approximately 36 months remaining on their sentence, a substance-abuse history documented in their Pre-sentencing Investigation report (PSI), and meet DSM-IV diagnostic criteria for drug or alcohol abuse or dependence are eligible to participate in the RDAP. The residential component of RDAP at FCI Morgantown consists of structured treatment programming, in accordance with BOP policy, lasting nine months (approximately 500 hours). Inmates attend RDAP group meetings five days each week, approximately three hours each day and reside in the housing unit designated only for inmates currently participating, or awaiting participation, in RDAP. Number of sessions and hours of treatment vary slightly by cohort, as well as within each cohort, due to extraneous variables (e.g., federal holidays, inmate illness, and conflicting institutional appointments for inmates).

\section{Participants}

Inmates meeting eligibility requirements are assigned to an RDAP treatment group based on the length of sentence remaining to be served. Approximately 30 inmates are assigned to each group. As a component of individualized treatment planning, within the first two weeks of treatment, inmates assigned to each group are administered a battery of psychological assessment instruments during two four-hour group meetings. Data from nine consecutive RDAP groups at FCI Morgantown was included in the current study.

Program "completers" were defined as those inmates who complete the 9-month RDAP group to which they were initially assigned. Program "non-completers" were inmates who started an RDAP group but did not complete with their cohorts due to a clinical decision to restart the inmate in a later RDAP group due to poor treatment progress, clinical decision to remove the inmate from RDAP due to poor therapeutic progress, or an inmate's decision to withdraw from the RDAP. Data obtained from four inmates who did not complete RDAP as a result their removal from the institution due to reasons outside of RDAP regulations (e.g., writ of habeas corpus, medical transfer) was excluded from analyses. Additionally, seven inmates were excluded from this original sample due to incomplete data sets. The final study sample consisted of 254 male inmates, with a $67.7 \%$ completion rate (172 completers, 82 non-completers) at FCI Morgantown. Completers averaged 169 sessions over the nine-month program, with an average of 509 hours of treatment programming. Non-completers averaged 80 sessions, and averaged 234 hours of treatment programming.

Basic Demographics. Basic demographics are summarized in Table 1. The mean age of RDAP participants was 36.15 ( $\mathrm{SD}=9.87$ ). 53.9\% self-identified as African-American, 34.6\% as Caucasian, $7.5 \%$ as Hispanic-American, $1.6 \%$ as Asian-American, $1.6 \%$ as Native American, and $.8 \%$ as other (i.e., Egyptian, Bi-racial). The average education for this sample was 12.09 years $(\mathrm{SD}=2.13)$. The majority $(51.2 \%)$ of the sample are Single/Never-married, $30.7 \%$ are Married/Common-law, 14.6\% are Divorced, and 3.5\% are Separated. Mean number of known biological children was $1.95(\mathrm{SD}=1.80)$. 
Substance-Abuse Data. Substance abuse data are summarized in Table 1. Ten categories of substances found in the Diagnostic and Statistical Manuel of Mental Disorders - Fourth Edition (DSM-IV) were employed in the current study to aid in the categorization of drug-use history. The average length of time each category of drug was abused are as follows: alcohol for 15.94 years $(\mathrm{SD}=10.66)$, amphetamine for 2.28 years $(\mathrm{SD}=4.88)$, cannabis for 12.42 years (9.78), cocaine for 5.32 years $(\mathrm{SD}=7.56)$, hallucinogens for 1.19 years $(\mathrm{SD}=3.82)$, opiates for 1.43 years $(\mathrm{SD}=4.12)$, sedatives for 1.35 years $(\mathrm{SD}=4.15)$, and inhalants, phencyclidine, and other drugs for fewer than one year. Voluntary and involuntary inpatient and outpatient treatment history was negligible, with the sample participating in an average of less than one program prior to current RDAP participation.

Criminal History Data. Criminal history data are summarized in Table 1. RDAP participants were asked to estimate the number of state and federal incarcerations as an adult. Reports ranged from one to thirty-three, with the mean number of incarcerations being 2.33 $(\mathrm{SD}=2.66)$. A maximum of 164 months of incarceration as an adult was reported and the mean number of months of incarceration was 36.61 ( $\mathrm{SD}=35.09)$. Current sentence ranged from twelve months to 216 months $(\mathrm{M}=60.96, \mathrm{SD}=37.69)$. Drug offenses accounted for $88 \%$ of the sample's current incarcerations.

\section{Measures}

Data utilized in the current project was sampled from a larger data pool compiled during an ongoing treatment-planning process of RDAP at FCI Morgantown. For the purposes of the current study, however, data from four psychological instruments was analyzed (Table 2), in addition to a review of records. All identifying data was removed from assessment data included in the current study.

General Ability Measure for Adults (GAMA; Naglieri \& Bardos, 1997). Inmate's intelligence was measured by the GAMA. This is a timed ( 25 minutes), nonverbal evaluation of general intellectual ability that may be administered in a group setting. Administration stimuli include a response sheet and a test booklet of colorful designs (designed to minimize the effects of color-blindness) which the test-taker examines and to which the test-taker responds. Four sample items are provided and explained by the test administrator to ensure understanding of the GAMA instructions. During the actual test administration, no assistance may be offered by the test-administrator. Directions for each item are written at an early elementary reading level (grade 2.4). The 66 items of the GAMA are organized into four subtests. First, the matching subtest requires the test-taker to examine shapes and colors, with the end goal of deciding which design option is identical to the target design. The analogies subtest involves understanding the relationships in a pair of abstract figures, with the end goal of recognizing a similar option in a different pair of figures. Third, the sequences subtest involves the analysis of the interrelationships of designs, with particular attention to the spatial and sequential aspects of the designs. Finally, the construction subtest involves the "analysis, synthesis, and rotation of spatial designs," with the end goal of completing the established pattern with one of the design options. 
Conversion of tallied subtest scores yields the GAMA IQ score, percentile, and confidence intervals. As is used with many tests of intelligence, GAMA IQ scores range from 43 to 156 , have a mean of 100 , and a standard deviation of 15 . Subtest scale scores have a mean of 10 and a standard deviation of 3. The GAMA was standardized on a nationally representative sample (according to the 1990 U.S. Census) of 2,360 adults ranging from 18-years-old to 96years-old. Average reliability coefficients range from .66 to .81 across age groups. Internal consistency of the GAMA IQ score was found to be slightly higher, with an average reliability coefficient across age groups of .90 (Naglieri \& Bardos, 1997). The GAMA IQ score has also demonstrated good correlations with WAIS-R Verbal IQ (.65), WAIS-R Performance IQ (.74), WAIS-R IQ (.75), K-BIT Vocabulary (.54), K-BIT Matrices (.72), and K-BIT IQ (.70).

Personality Assessment Inventory (PAI: Morey, 1991). Inmates' psychological symptoms were measured by the PAI. This is a 344-item, non-overlapping multi-scale personality test (Attachment A). The self-report format of the PAI allows for group administration. Responses to items are on a 4-point Likert-type scale, ranging from "Not True" to "Very True". The PAI contains four validity scales, including Negative Impression Management (NIM), Positive Impression Management (PIM), Inconsistency (INC), and Infrequency (INF). Elevations of Tscores $(\geq 65)$ on any of the validity scales suggest dishonest responding and render the PAI profile invalid and uninterpretable. The PAI also consists of 11 clinical scales: somatic complaints, anxiety, anxiety-related disorders, depression, mania, paranoia, schizophrenia, borderline features, antisocial features, alcohol problems, and drug problems. For the clinical scales, T-scores of 70 and higher are interpreted as significant for a clinical sample. The PAI has been well validated. See PAI manual for review of extensive validation research.

Paulhus Deception Scales (PDS; Paulhus, 1998). Potential dishonest responding by inmates were measured by the PDS. This 40-item self-report measure of social desirability is written at a $5^{\text {th }}$-grade reading level. PDS items are responded to on a 5-point Likert-type scale, ranging from "Not True" to "Very True" (Appendix B). The PDS consists of two 20-item scales: Impression Management (IM) and Self Deceptive Enhancement (SDE). The IM scale measures the degree to which the responder is attempting to make a positive or favorable impression in responses to the tests. Elevation of the IM scale is suggestive of deception and manipulation when elevated. The SDE scale measures both a generalized personality bias toward overconfidence and a tendency to minimize personal weaknesses. Elevation of the SDE scale is suggestive of defensiveness and, when extremely elevated psychopathy should be considered. A low SDE score may also indicate depression (true or feigned) in the responder. For the purposes of the current study, the Total PDS score was used in analyses to measure overall dishonest responding.

Data supporting the reliability and validity of the PDS is offered in the administration manual. On a sample of 603 "prison entrants", good internal consistency of the SDE scale (.72), IM scale (.84), and Total score (.86) were reported. Convergent and discriminant validity of the PDS are supported by reviews of nine studies in the administration manual.

Psychological Inventory of Criminal Thinking Styles (PICTS; Walters, 2001). The PICTS is an 80-item self-report measure developed within the BOP and primarily validated on corrections populations (White \& Walters, 1989; Walters \& White, 1989; Walters, 1995a; 
Walters, 1995b; Walters, 1997; Walters, Elliot, \& Miscoll, 1998) (Appendix C). The eight criminal thinking styles examined by the PICTS are those targeted by RDAP and hypothesized to proceed and sustain a criminal lifestyle (Walters \& White, 1989), as adapted from Yokelson and Samenow's (1976) thinking errors. T-scores of 60 or higher on any of the PICTS eight content scales are considered elevated. It has been reported, however, that offenders with a drug-abuse history tend to elevate the PICTS thinking style scores beyond that achieved by offenders with no personal history of drug abuse (as cited in Walters, 2001). All eight criminal thinking styles were included in primary analyses, and were considered for inclusion in secondary analyses, to explore their relationship with program completion. The PICTS is a relatively new psychological instrument with related empirical studies conducted primarily by the PICTS' author. Validity data is emerging.

Review of Relevant Records. Review of each RDAP participant's arrest record via the BOP computerized record system (SENTRY) was utilized to acquire official information on criminal history (i.e., number of incarcerations, history of violent offenses). The RDAP eligibility interview will be reviewed to obtain information on each inmate's history of substance abuse (i.e., duration of abuse of specific illegal substances).

\section{Procedure}

At FCI Morgantown, RDAP group members are administered a battery of psychological assessment instruments. This assessment process is conducted in a group setting during two fourhour group meetings within the first two weeks of treatment. This data is used in assisting RDAP treatment providers to individualize treatment plans and gain a better understanding of group members' psychological and behavioral histories. The assessment process was conducted by the author for the primary purpose of treatment planning within RDAP. Data analyzed in this study, therefore, was largely archival, with the exception of treatment completion status and substanceabuse history. Information regarding substance-abuse history was collected via review of each inmate's RDAP eligibility interview. Eligibility interviews are routinely conducted by RDAP staff prior to each inmate's enrollment in RDAP.

\section{Analytic Plan}

\section{Univariate and Bivariate Analyses}

As a first step, intercorrelations among all study variables were explored. Those variables found to be strongly correlated were examined to determine whether a reduction in total variables is warranted due to multicollinearity (i.e., highly correlated variables which may be found to measure the same construct). Next, a one-way analysis of variance (ANOVA) was conducted to explore whether dishonest responding, as measured by the Paulhus Deception Scale total score (PDS-Total), was significantly different between completers and non-completers. There was a significant difference completion status on $\operatorname{PDS}-\operatorname{IM}\left(F_{(1,252)}=4.311, p<.05\right)$, but no significant difference emerged for completion status on $\operatorname{PDS}-\operatorname{SDE}\left(F_{(1,252)}=1.057, p=.747\right)$. There was not a significant effect of completion status on PDS-Total $\left(F_{(1,252)}=1.649, p=.200\right)$. Mean PDS-Total for completers was $8.76(\mathrm{SD}=5.79)$ and for non-completers was 7.90 $(\mathrm{SD}=4.57)$. Given that interpretation of the PDS uses the evaluation of "higher" and "lower" 
scores, no subsequent analyses (e.g., Chi-square analyses) were warranted. Therefore, PDS-Total scores were not included as a covariant in subsequent analyses.

ANOVAs were calculated to explore the effects of completion status on continuous study variables. While results of these analyses are statistically informative, clinical significance of several study measures (i.e., PAI, PICTS, and GAMA) require interpretation based on predetermined cut-offs. For example, differences between PAI T-scores of 65 and 72 may not be significant via ANOVA, but the analysis of clinically elevated versus not elevated via Pearson's Chi-square analyses may allow for greater clinical utility of results. Therefore, PAI scores were recoded to reflect the $T \geq 70$ clinical cut-off, PICTS scores were recoded to reflect the $T \geq 60$ cutoff, and GAMA scores were recoded to reflect the IQ $=90$ floor of the Average IQ range.

Recoding sociodemographic data to allow for Pearson's Chi-square analyses also served two purposes. First, recoding categories of the raw data utilizing a median split was necessary in order to accurately address current hypotheses. This method of recoding data also replicates data coding utilized in similar studies reviewed. Therefore, recoding data via median split aids with ease of result interpretation and utility of findings. The following sociodemographic variables were recoded as indicated by median split: age, education, number of incarcerations, current sentence, and total time served. A median split was attempted when recoding length of drug use; however, only alcohol use (fourteen years), cannabis use (ten years), and cocaine (1 year), had median split values above zero. Therefore, to maintain consistency of recoding within the category of length of drug use, recoding reflected drug use lasting less than one year and one year or more of use (see Table 3).

Second, as a result of the wide variance of participants per cell, recoding of data was necessary to facilitate valid analyses (e.g., Chi-square requires $\mathrm{N}>5$ per cell). To accomplish this goal, categorical levels of several sociodemographic factors were collapsed to achieve appropriate cell counts (see Table 3). The ethnic groups of Hispanic-American, Asian-American, Native-American, and Other were collapsed into a collective "Other" category. The currentoffense categories of Property, Supervised Release Violation, and Other were collapsed into a collected "Other" category. The marital-status categories of Divorced and Separated were collapsed to form a "Divorce/Separated" category.

To decrease the chance of Type II errors in more complex and empirically informative analyses, a less-restrictive significance level was assigned to Pearson's Chi-square analyses in the current study. Therefore, statistically significant variables $(p<.05)$, as well as statistical trends at $\mathrm{p}<.075$, as identified by Pearson's Chi-square analyses were retained for multivariate analyses.

\section{Multivariate Analyses}

In an effort to help reduce Type I error, cross validation of multivariate analyses were attempted. The total sample was divided into a randomly selected testing sample $(\mathrm{n}=199)$ and a randomly selected cross-validation sample $(n=55)$. 
Logistic Regression. A logistic regression analysis is employed when prediction of a dependent dichotomous variable is the research goal. Therefore, to test the aforementioned hypotheses, the probability of the occurrence of a treatment-completion status (i.e., complete versus non-complete) was examined via a logistic regression analysis performed on the testing sample. Significant predictor variables, as identified by preliminary Pearson's Chi-square analyses, were entered into a logistic regression. The resultant statistical model served to identify significant independent variables. No definitive guidelines are available with regard to a required sample size to independent variables ratio. However, general guidelines ranging from 5:1 to 20:1 are widely accepted. Therefore, it is believed that statistical power was not jeopardized in the current study (e.g., Nielsen and Scarpitti, 2002).

The resultant statistical model was then cross validated on the randomly selected crossvalidation sample. Specifically, the original model was applied to the cross-validation sample of inmates to re-examine the predictive ability of the model.

Discriminant Function Analysis. Significant predictor variables identified by the logistic regression were then included in a discriminant function analysis performed on the testing sample. The primary objective of the discriminant function analyses (DFA) is to identify a set of variables that successfully predict group membership (i.e., completion status). For the purposes of the current study, conducting a DFA in addition to logistic regression allowed for a determination of the percentage of individuals who were correctly classified as completers or non-completers, beyond the probability of chance. (e.g., White et al., 1998).

The resultant significant predictor variables of the DFA were then cross-validated on the same randomly selected cross-validation sample utilized in the logistic regression replication process previously described. Replication of correct classification will serve to further validate the predictive power of the significant predictor variables.

Results

\section{Intercorrelations}

Intercorrelations among all study variables were examined. Variables with obvious construct similarities (e.g., drug/alcohol use variables) did not reveal significant correlations, as illustrated in Table 4. As such, a decision was made not to exclude or collapse any of these variables.

\section{Analyses of Sociodemographic Variables}

ANOVA results for continuous sociodemographic variables are summarized in Table 5. ANOVAs were conducted for each of the continuous predictor variables to explore general differences between completers and non-completers. Hypothesized relationships between completion status and age, IQ, and education were not supported by ANOVAs. Exploratory ANOVAs conducted on the remainder of study variables revealed two significant variables: a significant effect of length of current sentence on completion status was found $\left(\mathrm{F}_{(1,252)}=10.048\right.$, $\mathrm{p}<.05)$, and, also, total time served was found to significantly effect completion status $\left(\mathrm{F}_{(1,252)}=\right.$ 
$3.543, \mathrm{p}<.05)$.

Next, Pearson's Chi-square analyses of sociodemographic variables were conducted. Results are summarized in Table 3. As hypothesized, a trend was found between completion status and number of incarcerations $\left(\chi^{2}=4.410, \mathrm{df}=1, p<.075\right)$. Within the group of completers, the majority $(75 \%)$ had a history of two incarcerations or fewer, whereas the minority $(25 \%)$ had more incarcerations. No relationship was found between completion status and history of violent offenses. Exploratory analyses, however, revealed a significant relationship between completion status and length of current sentence $\left(\chi^{2}=11.578, \mathrm{df}=1, p<\right.$ $.001)$. Within the group of non-completers, the majority $(65.9 \%)$ have a current sentence 49 months or fewer. Non-completers had trends toward being more likely to have one year or more of alcohol abuse $(80.5 \%)\left(\chi^{2}=3.585, \mathrm{df}=1, p<.075\right)$ and less than one year of amphetamine abuse $(79.3 \%)\left(\chi^{2}=3.574, \mathrm{df}=1, p<.075\right)$. Completers were more likely to have one year or more of cannabis abuse $(90.1 \%)\left(\chi^{2}=4.554, \mathrm{df}=1, p<.05\right)$.

\section{Analyses of Validity Scales}

Validity scale scores for the PAI are summarized in Table 5. Fifty-seven (22.4\%) of the PAI profiles for the total sample were found to be clinically invalid based on elevations $(\mathrm{T} \geq 70)$ on any of the four PAI validity scales. No significant effects on completion status were found for each of the PAI validity scales (i.e., Inconsistency, Infrequency, Negative Impression Management, and Positive Impression Management) when explored by ANOVAs (Table 6). Pearson's Chi-square analyses were conducted to explore the effects of clinically elevated PAI validity scales (i.e., $\mathrm{T} \geq 70$ and $\mathrm{T}<70$ ). Because there were fewer than five completers with clinically elevated Inconsistency scores and fewer than five completers and non-completers with clinically elevated Positive Impression Management scores, Chi-square analyses could not be computed for these scales. Pearson's Chi-square analyses for the Infrequency and Negative Impression Management were not significant (Table 7). In sum, no significant relationship between completion status and PAI validity scales were found. Further, from a practical perspective, invalid profiles are common among inmate populations. Therefore, it was decided to retain these profiles in further analyses and empirically evaluate the practical utility of individually elevated clinical, treatment, and interpersonal scales.

Validity scale scores for the PICTS are summarized in Table 5. Sixty-eight $(26.8 \%)$ of the PICTS profiles for this sample were found to be clinically invalid. No significant effects on completion status were found for each of the PICTS validity scales (i.e., Confusion-Revised and Defensiveness-Revised) when explored by ANOVAs (Table 6). Pearson's Chi-square analyses conducted to examine the effects of clinically elevated and not-elevated PICTS validity scales (i.e., $\mathrm{T} \geq 60$ and $\mathrm{T}<60$ ). Because there were fewer than five completers and non-completers with clinically elevated Defensiveness-Revised scores, Pearson's Chi-square analyses could not be computed for this scale. Pearson's Chi-square analysis for Confusion-Revised scale was nonsignificant (Table 7). From a practical perspective, invalid profiles are common among inmate populations, and thus invalid profiles will be included in the further analyses. 


\section{Analyses of PAI Clinical and Treatment Scales}

Hypothesized relationships between completion status and depressed mood, antisocial characteristics, and schizotypal symptoms were not supported. Exploratory ANOVAs were conducted on remaining PAI clinical, treatment, and interpersonal scales. Results are summarized in Table 8. A significant effect on completion status by Drug Problem (PAI-DRG) scores was found $\left(\mathrm{F}_{(1,252)}=6.363, \mathrm{p}<.05\right)$.

Again, hypothesized effects of clinically elevated and not elevated (i.e., $\mathrm{T} \geq 70$ and $\mathrm{T}<$ 70) Depression, Antisocial, or Schizotypal scores (i.e., $T \geq 70$ ) were not supported by Pearson's Chi-square analyses (Table 9). Exploratory Pearson's Chi-square analyses, however, revealed the majority of completers $(83.7 \%)$ had clinically elevated PAI-DRG scores $\left(\chi^{2}=9.071, \mathrm{df}=1, p<\right.$ $.05)$. Pearson's Chi-square analyses could not be computed for the Suicidal Ideation, Nonsupport, and Treatment Rejection scales because at least one cell contained fewer than five subjects (Table 9).

\section{Analyses of PICTS Scales}

Hypothesized effects on completion status by Mollification, Entitlement, and Superoptimism scales were not supported by ANOVA results. Further, completion status was not found to be significantly related to any of the remaining PICTS scales. ANOVA results are summarized in Table 10.

Pearson's Chi-square analyses of clinically elevated and not elevated (i.e., $\mathrm{T} \geq 60$ and $\mathrm{T}<$ 60) Mollification, entitlement, and superoptimism scales were non-significant (Table 11). Exploratory Pearson's Chi-square analyses revealed the majority of completers $(70.9 \%)$ had clinically elevated Historical (PICTS-HIS) scores $\left(\chi^{2}=4.622, \mathrm{df}=1, p<.05\right)$.

\section{Logistic Regression}

Using significant variables identified by Pearson's Chi-square analyses (i.e., number of incarcerations, length of current sentence, length of alcohol use, length of amphetamine use, length of cannabis use, PAI-DRG, and PICTS-HIS) as predictor variables, a logistic regression analyses was performed with completion of RDAP as the dependant variable. A total of 199 cases (excluding the $\mathrm{n}=55$ cross-validation sample) were analyzed and the full model was significantly reliable $\left(\chi^{2}=29.895, \mathrm{df}=7, p<.0001\right)$. This model accounted for $13.9 \%$ and $19.7 \%$ of the variance in completion status, as indicated by the Cox \& Snell R Square and Nagelkerke R Square, respectively. An impressive $89.9 \%$ of completers were successfully predicted, but only $32.9 \%$ of predictions for non-completers were accurately predicted. Overall, $72.4 \%$ of predictions formed by this model were accurate. Two of the seven predictor variables entered into this Logistic Regression were retained as significant predictors of treatment completion status (Table 12). To estimate the increase in odds of membership in the target group (completers) for each level of the predictor variable, while controlling for other predictors in the model, odds ratios for each significant predictor variable were examined. Odds ratios for current sentence revealed a current sentence greater than 49 months is associated with an increase in the odds of completion by a factor of 2.26 and clinically elevated PAI-DRG scores were associated 
with an increase in the odds of completion by a factor of 2.59. Overall, the predictive model including these two variables yielded a percentage accuracy in classification (PAC) of $72.4 \%$. Sensitivity of this model was $89.9 \%$, with a lower specificity $32.8 \%$. The positive predictive value was $75.2 \%$, with a lower negative predictive value of $58.8 \%$ (Table 13 ).

These two significant predictor variables were then entered to form a reduced logistic regression analyses (Table 12). Examination of the cross-validation sample $(n=55)$ with the reduced model was not found to be statistically reliable $\left(\chi^{2}=2.772, \mathrm{df}=2, p=.256\right)$.

\section{Discriminant Function Analysis}

Data from the 199-case testing sample was analyzed in a single discriminant function analysis, maintaining the 55-case cross-validation sample for attempted replication of the resultant model. A discriminant analysis was performed with completion of RDAP as the dependent variable and the significant predictor variables identified in the initial logistic regression analysis (i.e., length of current sentence and PAI-DRG) as predictor variables. Prior probabilities for group membership, based on the number of cases that fall into each completion category instead of standard probability of chance $(50 \%)$, were $30.7 \%$ for non-completers and $69.3 \%$ for completers. The value of this function was significantly different for completers and non-completers $\left(\chi^{2}=19.120, \mathrm{df}=2, p<.0001\right)$. The pooled within-group correlations between predictor variables and the discriminant function suggested that both variables were good predictors of completion status. PAI-DRG was positively correlated with the discriminant function value $(\mathrm{r}=.750)$, suggesting that participants with clinically elevated PAI-DRG scores were more likely to complete RDAP. Also, length of current sentence was positively correlated with the discriminant functioning value $(\mathrm{r}=.672)$, suggesting that participants with a current sentence longer than 49 months were more likely to complete in RDAP. Overall, the discriminant function successfully predicted completion status for $72.4 \%$ of cases, with accurate predictions being made for $93.5 \%$ of completers (Table 14). Unfortunately, $24.59 \%$ of noncompleters were accurately predicted, which is $6.1 \%$ worse than by chance alone.

The same discriminant function model was then applied to the 55-case cross-validation sample. Prior probabilities for group membership, based on the number of cases that fall into each completion category, were $38.2 \%$ for non-completers and $61.8 \%$ for completers. The value for this discriminant function analysis was not significant $\left(\chi^{2}=2.600, \mathrm{df}=2, p=.273\right)$. Overall, the discriminant function successfully predicted completion status for $70 \%$ of cases. Prediction of non-completion, however, was wrong $85.7 \%$ of the time, $47.5 \%$ worse than by chance alone.

\section{Post-Hoc Analyses}

To more carefully understand characteristics of non-completers, additional post-hoc analyses were conducted. In the current sample, approximately $20 \%$ of the non-completers ceased participation after only 125 hours (first quarter of total program), while approximately $20 \%$ of non-completers ceased participation in the final quarter of the total program (completion of 375 hours or more). Exploratory ANOVAs revealed significant mean differences on PAI Inconsistency scale $\left(\mathrm{F}_{(1,28)}=9.065, \mathrm{p}<.01\right)$. Significant differences on the following PAI scales 
were also found: Paranoia $\left(\mathrm{F}_{(1,28)}=6.406, \mathrm{p}<.05\right)$, Borderline $\left(\mathrm{F}_{(1,28)}=4.324, \mathrm{p}<.05\right)$, Antisocial $\left(\mathrm{F}_{(1,28)}=7.338, \mathrm{p}<.05\right)$, Suicidal Ideation $\left(\mathrm{F}_{(1,28)}=7.064, \mathrm{p}<.05\right)$, and Non-Support $\left(\mathrm{F}_{(1,28)}=5.525, \mathrm{p}<.05\right)$. For all significant ANOVAs, early non-completers had higher scale means. Pearson's Chi-square analyses could not be conducted to explore differences between elevated and not elevate scale-scores due to the small sub-sample size. No PICTS-scale mean differences were found.

Given these differences, early non-completers $(n=15)$ were then compared with a sample of completers $(n=30)$. Based on a 2:1 ratio, completers were matched to non-completers based on age and ethnicity. Exploratory ANOVAs revealed significant mean differences on the PAI Inconsistency scale $\left(\mathrm{F}_{(1,44)}=4.962, \mathrm{p}<.05\right)$, with early non-completers having a higher mean score. No other mean differences were found for the remaining PAI scales. On the PICTS, the only significant mean difference was found for the Cognitive Indolence scale $\left(\mathrm{F}_{(1,28)}=6.051\right.$, $\mathrm{p}<.05$ ), with completers having a higher mean score. Again, due the small sub-sample size, Pearson's Chi-square analyses could not be conducted to explore differences between elevated and not-elevated scale scores.

\section{Discussion}

\section{Summary of Results}

Significant group differences and trends emerged in the areas of criminal and substanceabuse histories. Specifically, RDAP completers were more likely to have had a shorter incarceration history (i.e., two or fewer) than non-completers, but non-completers were more likely to have served shorter sentences (i.e., 49 months or fewer) than completers. Noncompleters tended to have had alcohol abuse histories lasting at least one year, but shorter amphetamine-abuse histories. Completers tended to have cannabis-abuse histories of one year or more. Hypothesized group differences of age, IQ, education, and history of violence were not supported by the current data.

PAI profiles were invalid for $22.4 \%$ of completers and non-completers combined. Completers and non-completers were equally as likely to present with invalid PAI profiles. While not ideal, from a clinical perspective it is not uncommon for inmates in treatment to provide dishonest psychological data (Richards \& Henry, 2003; McNulty, Forbey, Graham, BenPorath, Black, Anderson, \& Burlew, 2003). When self-report is the primary source of psychological data, empirical data exploring the clinical utility of invalid data is a resource. Further, no significant differences between completers and non-completers were identified when examining mean validity-scale scores. Additionally, there were no differences between clinically elevated and sub-threshold PAI validity-scale scores. As such, all PAI profiles, valid or invalid, were included in data analyses to allow the exploration of possible effects of data to assist in discriminating treatment completers from non-completers.

PAI clinical and treatment scales were first analyzed with scores on a continuum. On this level, group differences were found on PAI-DRG, a scale measuring drug use and related social, occupational, and recreational difficulties. When PAI scales were recoded to reflect clinical elevations $(\mathrm{T} \geq 70)$ and below threshold scores, completers tended to have clinically elevated 
PAI-DRG scores. PAI-SUI, PAI-NON, and PAI-RXR could not be explored due to an insufficient number of completers and non-completers with clinically elevated scores. Finally, hypothesized group differences on PAI-DEP, PAI-ANT, and PAI-SCZ were not empirically supported.

Similar to PAI profiles in this study, PICTS profiles were invalid for $26.8 \%$ of completers and non-completers combined. As previously described, self-report data provided by inmates is often invalid (Richards \& Henry, 2003; McNulty et al., 2003). Further, no between-group PICTS validity-scale differences were shown. As such, all PICTS profiles were included in data analyses.

No differences on any PICTS scales were found between completers and non-completers. When PICTS scores were recoded to reflect clinical elevations $(T \geq 60)$ and sub-threshold scores, more completers were found to have clinically elevated PICTS-HIS scores (i.e., historical use of general criminal thinking styles). Criminal thinking styles hypothesized to relate to completion status (i.e, Mollification, Entitlement, and Superoptimism) were not found to be more common among completers or non-completers.

In sum, seven variables were identified to be significantly related to, or a trend toward, program completion status. Specifically, two criminal-history variables (i.e., number of incarcerations and length of current sentence), three drug-use variables (i.e., length of alcohol use, amphetamine use, and cannabis use), and one scale from each of the comprehensive psychological assessment instruments (i.e., PAI-DRG and PICTS-HIS) were all identified as potential predictors of program completion.

To determine the best statistical predictors of program completion, the seven predictor variables were analyzed using a logistic regression. Of those, only two variables were retained. RDAP participants with current sentences longer than 49 months to complete had 2.26 times greater odds of completing RDAP than those who had shorter sentences, and RDAP participants with clinically elevated PAI-DRG scores had 2.59 greater odds of completing RDAP than those without elevated PAI-DRG scores. Overall, the predictive model including these two variables yielded a percentage accuracy in classification (PAC) of $72.4 \%$. It should be noted, however, that a crude prediction of completion status, assuming all RDAP participants will belong to the predominant group (completers), yields a PAC of $69.3 \%$. Therefore, overall predictive ability of this model should be interpreted cautiously.

This model of predictor variables, as assessed by DFA, produced a hit rate of $72.4 \%$. As assessed by logistic regression, this model was able to correctly classify $75.2 \%$ (positive predictive value) of the completers in this sample. When only looking at completers, $89.9 \%$ were correctly classified (sensitivity). This suggests good positive predictive ability. The model, however, did not have as robust an ability to successfully predict non-completers. Of the entire sample, this model was able to correctly classify only $58.8 \%$ of non-completers (negative predictive value). Further, when solely examining non-completers, only $32.8 \%$ were correctly classified (specificity). This model is better able to predict program completers than noncompleters. Unfortunately, results of the logistic regression and discriminant function analyses were not replicated on the cross-validation sample, suggesting the need for replication before more definitive models of prediction can be certified. 


\section{Clinical Implications}

In the current study identified predictive factors of program completion (i.e., PAI-DRG and longer sentences) are predominantly historical. As such, the cost of misclassifying completers or non-completers does not necessarily impact pre-treatment efforts. Rather, results of this study (i.e., the model's propensity to accurately predict completers versus noncompleters) offer a variety of other research and clinical implications.

It is logical that RDAP participants would report histories of drug abuse. While it was hypothesized that individuals with specific drug-use histories would be less likely to complete RDAP, actual study findings indicate more general drug-use history effects on completion status. The PAI-DRG scale measures the severity of an individual's general drug use history, including the negative impact it has had on various social, occupational, and recreational aspects of a person's life. One reason these individuals may fair better in RDAP is that a large portion of the program targets these areas which RDAP completers have independently identified as personally relevant. Another reason these individuals may be more likely to complete RDAP is that their pre-incarceration lifestyles, including drug use, may have been punishing to the extent that potential completers have been motivated to change to avoid future punishing drug-use-related consequences. This possibility can be related to previous findings by Pelissier and colleagues (2000; 2002; in press) regarding RDAP completers tendency to present in the contemplation or maintenance stage of change.

In contrast to previous RDAP studies (Pelissier, 2000; Pelissier, Camp, \& Motivans, 2002; Pelissier, in press), individuals who had longer sentences were more likely to complete RDAP in the current study. Because an individual's current sentence is not susceptible to dishonest responding, as compared to other self-report information (e.g., PAI and PICTS), the predictive ability of sentence length may be more reliable. One reason for the predictive ability of longer sentences may be similar to that described for elevated PAI-DRG. Specifically, completers may have been punished for their criminal behaviors to such a degree that it has effectively caused some level a change in their behaviors or cognitions. Completers' motivation for change however, may not be the sole reason for their RDAP success. Pelissier (2000) found non-completers tended not to be eligible to benefit from the one-year sentence reduction offered upon the successful completion of RDAP. Along the same lines, current findings of the predictive power of longer sentences may be related to completers' motivation to capitalize on the sentence-reduction policy. Data necessary to test this theory (i.e., meeting eligibility criteria) was not collected in the current study to limit the already expansive list of variables.

While many variables examined in the current study were found not to be significantly predictive of program completion, descriptive data can also be used to guide general treatment efforts. First, regardless of completion status, participants tended to have IQs in the average range or higher, but also tended to have less than high-school educations. This suggests the need for academic and/or vocational training for RDAP participants. Fortunately, participation in GED classes is generally mandatory for BOP inmates without a high-school degree, but perhaps more extensive educational programming for RDAP participants should be explored. 
Second, each PAI clinical and treatment scale was elevated by at least one RDAP participant in this study. Pre-treatment planning, then, could benefit from results of the PAI, or a similar comprehensive psychological inventory. Perhaps closer monitoring of symptoms, or participation in additional treatment opportunities (e.g., group therapy) for specific psychological areas, could be recommended to targeted RDAP participants. Third, each of the eight PICTS criminal thinking style scales were elevated by at least $26.8 \%$ of participants. The criminal thinking scales of cut-off, superoptimism, and cognitive indolence were elevated by more than half of all participants. This supports the need for the criminal-thinking module of RDAP. Pretreatment planning, however, may benefit from PICTS results indicating which criminal thinking errors are most predominant for each participant. Such information may help treatment providers better assess an individual's criminal-thinking tendencies and provide more structured cognitivemodification strategies for these individuals.

Finally, as examined in some non-RDAP treatment retention studies (e.g., McCaul, Svikis, \& Moore, 2001; Nielson \& Scarpetti, 2002), examination of differences between subgroups within the total sample was conducted. In the current sample, approximately $20 \%$ of the non-completers ceased participation after only 125 hours (first quarter of total program), while approximately $20 \%$ of non-completers ceased participation in the final quarter of the total program (completion of 375 hours or more). Exploratory analyses found early non-completers had higher mean scores on the following PAI scales: Inconsistency, Paranoia, Borderline, Antisocial, Suicidal Ideation, and Non-Support. This suggests the possibility that Axis II characteristics may distinguish early non-completers from late non-completers. No PICTS mean differences emerged. Early non-completers were found have a significantly higher mean validityscale score on the PAI (Inconsistency) than the matched sub-sample of completers. Interestingly, however, completers were found to have a significantly higher mean score on the PICTS Cognitive Indolence scale. These results suggest the possibility that non-completers are not a homogeneous group. Further, early non-completers and completers appear to present with significantly different characteristics, and thus, comparison of these groups may be warranted. Given the high possibility of Type I error on these post-hoc analyses, these results should be cautiously interpreted. Additionally, future research could seek to replicate these findings on larger samples. Gaining a better understanding of completers and non-completers may allow for a more economical use of therapeutic resources for identified sub-groups of RDAP participants.

\section{Limitations and Future Research}

The greatest limitation of the current study is the increased chance of Type I error. Because most hypotheses were not supported, exploratory analyses were conducted, totaling 60 variables examined. As a result, the number of statistical analyses actually conducted was greater than those planned. Planned cross-validation analyses as components of the logistic regression and discriminant function analysis were included in the current study to help control Type I error. Unfortunately, logistic regression and discriminant function analysis cross validations were unsuccessful. As a result, Type I error remains a significant concern. While the current sample was relatively large, cross validation of the current findings on a larger sample is recommended. 
Another sampling concern is the high percentage of technically invalid PAI and PICTS profiles. As previously discussed, invalid self-report data is not uncommon among inmate populations (Richards \& Pai, 2003; McNulty et al., 2003) and there was no statistical difference between completers and non-completers in the current study. Therefore, a decision was made to include these cases in the current study for the sake of clinical utility. Empirically, however, analyses may have yielded different results had only valid profiles been included. ${ }^{1}$ This would have allowed for analyses of the predictive ability of true symptoms, rather than self-reported psychological symptoms and maladaptive cognitions which were likely distorted to some degree.

While the focus of the current study was to provide a clinically useful checklist of symptoms which may help predict RDAP completion, examining data on a categorical basis, rather than on a continuum may have resulted in a less sensitive approach to the data. For example, due to cell-count requirements for Pearson's Chi-square analyses, participants of several ethnic groups were crudely combined to form an "Other" category. Future research may consider limiting analyses to sufficiently large sub-samples of ethnic groups.

RDAP participants' interactions with children should also be considered. Interestingly, in the current sample, $74.8 \%$ reported having at least two children. Often times these fathers do not have regular contact with their children and have served as poor role models for children with whom they do have contact. Further examination of the parent/child dynamic of RDAP participants is recommended to help guide future parent training programs for this population.

This is the first study to examine the PICTS ability to predict RDAP completion. Results of the current study suggest no significant predictive ability of this measure. Since the criminal thinking errors measured by the PICTS comprise a significant module of RDAP, better understanding of the utility of this measure is warranted. At present, additional research is needed to broaden empirical understanding of the predictive ability of the PICTS. For example, studies including inmates from different security levels, or female inmates, may yield different results. Similarly, RDAP participants at FCI Morgantown are a fairly homogeneous group (e.g., male, low security level, predominantly non-violent and incarcerated for drug related offenses); therefore, replication of all aspects of the current study should be conducted on various RDAP samples.

Given the differences of the current results as compared to previous RDAP related research, further exploration of predictive factors of RDAP completion are warranted. For example, while predictive factors may be related to participants' personal stage of change, formal assessment of participants' preparedness for personal change utilized in previous RDAP studies (Pelissier, 2000; Pelissier, Camp, \& Motivans, 2002; Pelissier, in press), were not included in the current study. RDAP participants' eligibility to benefit from the one-year sentence-reduction policy following RDAP completion, assessed by Pelissier and colleagues, was also beyond the scope of the current study. Examination of this factor with a low-security sample should be considered for future research.

Finally, exploring other areas in the prediction of RDAP completion is warranted. For example, perhaps drug treatment specialists' (DTS) level of training may affect a RDAP treatment group's completion rate. The ethnicity of a DTS may also be examined for possible 
inter-ethnic differences in RDAP participants' completion status (e.g., Kang et al., 1991). Similarly, perhaps DTS gender may affect participants' completion status. Another area to explore may also be inter-cohort factors; perhaps dynamics within the cohort affect an individual's progress and eventual completion status. While the current study expanded upon previous findings, it is evident that more empirical understanding of this area is needed. 


\section{References}

Bleiberg, J. L., Devlin, P., Croan, J., \& Briscoe, R. (1994). Relationship between treatment length and outcome in a treatment community. International Journal of the Addictions, 29, 729-740.

Carroll, K. M., Rounsaville, B. J., \& Gawin, F. H. (1991). A comparative trial of psychotherapies for ambulatory cocaine abusers: Relapse prevention and interpersonal psychotherapy. American Journal of Drug and Alcohol abuse, 17, 229-247.

Clements, R. (2002). Psychometric properties of the Substance Abuse Subtle Screening Inventory-3. Journal of Substance Abuse Treatment, 23, 419-423.

Condelli, W. S. \& Hubbard, R. L. (1994). Relationship between time spent in treatment and client outcomes from therapeutic communities. Journal of Substance Abuse Treatment, 11, 25-33.

DeMaria, P. A., Sterling, R., \& Weinstein, S. P. (2000). The effect of stimulant and sedative use on treatment outcome of patients admitted to methadone maintenance treatment. American Journal on Addictions, 9(2), 145-153.

Eisenberg, M., \& Fabelo, T. (1996). Evaluation of Texas correctional substance abuse treatment initiative: The impact of policy research. Crime \& Delinquency, 42, 296-308.

Federal Bureau of Prisons (n.d.) Retrieved April 15, 2005 from http:/www.bop.gov

Gainey, R. R., Wells, E. A., Hawkins, J. D., \& Catalano, R. F. (1993). Predicting treatment retention among cocaine users. The International Journal of the Addictions, 28(6), 487505.

Gawin, F. H., Kleber, H. D., Byck, R., Rounsaville, B. J., Kosten, T. R., Jatlow, P. I., \& Morgan, C. (1989). Desipramine facilitation of initial cocaine abstinence. Archives of General Psychiatry, 46, 117-121.

Gibbs, T. (2000). Substance abuse treatment and recidivism: An assessment of predictive factors from a residential program. Dissertation Abstracts International Section A: Humanities \& Social Sciences, 61(3-A), 1174.

Gilmore, J. D., Lash, S. J., Foster, M. A., \& Blosser, S. L. (2001). Adherence to substance abuse treatment: Clinical utility of two MMPI-2 scales. Journal of Personality Assessment, 77(3), 534-540.

Hiller, M. L., Knight, K., \& Broome, K. M. (1998). Legal pressure and treatment retention in a national sample of long-term residential programs. Criminal Justice \& Behavior, 25(4), 463-381.

Kang, S-Y., Kleinman, P. H., \& Todd, T. (1991). Familial and individual functioning in a sample of adult cocaine abusers Journal of Drug Issues, 21(3), 579-592.

Kellogg, S., Ho, A., Bell, K., Schluger, R. P., McHugh, P. F., McClary, K. A., \& Kreek, M. J. (2002). The Personality Assessment Inventory drug problems scale validity analysis. Journal of Personality Assessment, 79, 73-85.

Knight, K., Simpson, D. D., Chatham, L. R., \& Camacho, L. M. (1997). An assessment of prison-based drug treatment: Texas' in-prison therapeutic community. Journal of Offender Rehabilitation, 24, 75-100.

Knight, D. K., Logan, S. M., \& Simpson, D. D. (2001). Predictors of program completion for women in residential substance abuse treatment. American Journal of Drug Abuse, 27(1), $1-18$.

Knight, K., Simpson, D. D., \& Hiller, M. L. (2002). Screening and referral for substance-abuse 
treatment in the criminal justice system. In Treatment of Drug Offenders: Policies and Issues (pp259-272). New York: Springer Publishing.

Krebs, C. P., Brady, T., \& Laird, G. (2003). Jail-based substance user treatment: an analysis of retention. Substance Use \& Misuse, 38(9), 1227-1258.

Lamb, R. J., Kirby, K. C., \& Platt, J. J. (1996). Treatment retention, occupational role, and cocaine use in methadone maintenance. American Journal on Addictions, 5(1), 12-17.

Langan, N. P. \& Pelissier, B. M. M. (2001). The effect of drug treatment on inmate misconduct in federal prisons. Journal of Offender Rehabilitation, 34(2), 21-30.

Leshner, A. I. (1997). The National Institute on Drug Abuse (NIDA) drug abuse treatment outcome (DATOS). Psychology of Addictive Behavior, 11(4), 211-215.

McCaul, M. E., Svikis, D. S., \& Moore, R. D. (2001). Predictors of outpatient treatment retention: Patient versus substance use characteristics. Drug \& Alcohol Dependence, 62(1), 9-17.

McCollister, K. E. \& French, M. T. (2002). The economic cost of substance-abuse treatment in criminal justice settings. In Treatment of Drug Offenders: Policies and Issues (pp. 22-37). New York: Springer Publishing.

McLellan, A. T., Luborsky, L., O’Brien, C. P., Woody, G. E., \& Druley, K. A. (1982). Is treatment for substance abuse effective? JAMA, 247(10), 1423-1428.

McNulty, J. L., Forbey, J. D., Graham, J. R., Ben-Porath, Y. S., Black, M. S., Anderson, S. V., \& Burlew, A. K. (2003). MMPI-2 validity scale characteristics in a correctional sample. Assessment, 10(3), 288-298.

Morey L, C. (1991). Personality Assessment Inventory: Professional manual. Odessa, FL:

Psychological Assessment Resources.

Morey, L. C., \& Quigley, B. D. (2002). The use of the Personality Assessment Inventory (PAI) in assessing offenders. International Journal of Offender Therapy and Comparative Criminology, 46(3), 333-349.

Naglieri, J. A. \& Bardos, A. N. (1998). General Ability Measure for Adults (GAMA). Minneapolis: NCS Assessments.

Nielsen, A. L. \& Scarpitti, F. R. (2002). Predicting retention in a therapeutic community for incarcerated substance abusers. Journal of Offender Rehabilitation, 3(3), 47-65.

Paulhus, D. L. (1998). Paulhus Deception Scales (PDS): The Balanced Inventory of Desirable Responding-7. North Tonawanda, NY: Multi-Health Systems, Inc.

Pelissier, B.M. (In press). Gender Differences in Treatment Entry and Retention Among Prisoners with Substance Abuse Histories. American Journal of Public Health.

Pelissier, B. (2000). BOP TRIAD Drug Treatment Evaluation Three-Year Outcome Report. ORE Report.

Pelissier, B. (2000). Antisocial Personality and Depression Among Incarcerated Drug Treatment Participants. Journal of Substance Abuse, 11(4), 379-393.

Pelissier, B.M.M., Camp, S.D., Gaes, G.G., Saylor, W.G., \& Rhodes, W. (2003). Gender Differences in Outcomes from Prison-Based Residential Treatment. Journal of Substance Abuse Treatment, 24, 1-12.

Pelissier, B., Camp, S.D., \& Motivans, M. Staying in Treatment: How Much Difference is There From Prison to Prison? Psychology of Addictive Behaviors, 17(2), 134-141.

Pelissier, B.M., Rhodes, W., Saylor, W.G., Gaes, G.G., Camp, S.D., Vanyur, S.D., \& Wallace, S. (2001). TRIAD Drug Treatment Evaluation Project. Federal Probation, 65(3), 3-7.

Pelissier, B., Wallace, S., O’Neil, J.A., Gaes, G., Camp, S., Rhodes, W., \& Saylor, W. (2001). 
Federal Prison Residential Drug Treatment Reduces Substance Use and Arrests After Release. American Journal of Drug and Alcohol Abuse, 27(2), 315-337.

Peters, R. H., Greenbaum, P. E., Steinberg, M. L., Carter, C. R., Ortiz, M. M., Fry, B. C., \& Valle, S. K. (2000). Effectiveness of screening instruments in detecting substance use disorders among prisoners. Journal of Substance Abuse Treatment, 18, 349-358.

Ravndal, E. (1994). Self-reported depression as a predictor of dropout in a hierarchical therapeutic community. Journal of Substance Abuse Treatment, 11(5), 471-479.

Ravndal, E. \& Vaglum, P. (1991a). Psychopathology and substance abuse as predictors of program completion in a therapeutic community for drug abusers: A prospective study. Acta Psychiatrica Scandinavica, 83, 217-222.

Ravndal, E. (1991b). Changes in antisocial aggressiveness during treatment in a hierarchical therapeutic community: A prospective study of personality changes. Acta Psychiatrica Scandinavica, 84(6), 524-530.

Richards, H. J. \& Pai, S. M. (2003). Deception in prison assessment of substance abuse. Journal of Substance Abuse Treatment, 24, 121-128.

Rowan-Szal, G. A., Chatham, L. R., \& Simpson D. D. (2000). Importance of identifying cocaine and alcohol dependent clients. American Journal on Addictions, 9(1), 38-50.

Saxon, A. J., Wells, E. A., \& Fleming, C. (1996). Pre-treatment characteristics, program philosophy and ancillary services as predictors of methadone maintenance treatment outcome. Addiction, 91(8), 117-121.

Shearer, R. A. \& Ogan, G. D. (2002). Voluntary participation and treatment resistance in substance abuse treatment programs. Journal of Offender Rehabilitation, 34(3), 31-45.

Substance Abuse and Mental Health Data Archives, (n.d.). Results from the National Survey on Drug Abuse and Mental Health: National findings. Retrieved October 14, 2003, from http://www.samhasa.gov/oas/NHSDA/2k2NSDUH/Results/2k2results.htm\#chap8

Valle, S. K. \& Humphrey, D. (2002). American prisons as alcohol and drug treatment centers: A twenty-year reflection, 1980 to 2000. Alcoholism Treatment Quarterly, 20, 83-106.

Veach, L. J., Remley, T. P., Kippers, S. M., \& Sorg, J. D. (2000). Retention predictors related to intensive outpatient programs for substance use disorders. American Journal of Drug and Alcohol Abuse, 26(3), 417-428.

Vigdal, G. L. \& Stadler, D. W. (1996). Assessment, client treatment matching, and managing the substance abusing offender. In Drug Abuse Treatment Behind Bars: Prison Based Strategies for Change (pp. 17-43). Westport, CT: Praeger.

Walters, G. D. \& White, T. W. (1989). The thinking criminal: A cognitive model of lifestyle criminality. Criminal Justice Research Bulletin, 4(4).

Walters, G. D. (1995a). The Psychological Inventory of Criminal Thinking Styles: Part I. Reliability and preliminary validity. Criminal Justice and Behavior, 22, 307-325.

Walters, G. D. (1995b). The Psychological Inventory of Criminal Thinking Styles: Part II. Identifying simulated response sets. Criminal Justice and Behavior, 22(4), 437-445.

Walters, G. D. (1997). A confirmatory factor analysis of the lifestyle criminality screening form. Criminal Justice and Behavior, 24(2), 294-308.

Walters, G. D. (2001). Psychological Inventory of Criminal Thinking Styles: Professional manual. (Available from G. D. Walters via E-mail at gwalters@bop.gov).

Walters, G. D., Elliot, W. N., \& Miscoll, D. (1998). Use of the Psychological Inventory of Criminal Thinking Styles in a group of female offenders. Criminal Justice and Behavior, 25(1), 125-134. 
White, J. M., Winn, K. I., \& Young, W. (1998). Predictors of attrition from an outpatient chemical dependency program. Substance Abuse, 19(2), 49-59.

Wickizer, T., Maynard, C., Atherly, A., Fredrick, M., Koepsell, T., Krupski, A., \& Stark, K. 1994). Completion rates of clients discharged from drug and alcohol treatment programs in Washington state. American Journal of Public Health, 84(2), 215-221.

Yochelson, S. \& Samenow, S. E. (1976). The criminal personality: Vol. 1. A profile for change. New York: Jason Aronson. 


\section{Appendix A}

Personality Assessment Inventory (PAI; Morey, 1991) 
Appendix B

Paulhus Deception Scales (PDS; Paulhus, 1998) 
Appendix C

Psychological Inventory of Criminal Thinking Styles (Walters, 1991) 


\section{Footnotes}

${ }^{1}$ For exploratory purposes, analyses were conducted on valid-only PAI profiles. ANOVAs conducted on valid-only PAI profiles did not yield any significant mean differences. Pearson's Chi-square analyses on valid PAI profiles produced similar results to the analyses on the total sample, showing the majority of completers (86.4\%) had clinically elevated Drug Problem scores $\left(\chi^{2}=9.287, \mathrm{df}=1, p<.01\right)$. For exploratory purposes, analyses were also conducted on validonly PICTS profiles. ANOVAs conducted on valid-only PICTS profiles did not yield any significant mean differences. Pearson's Chi-square analyses on valid PICTS profiles produced two significant results. The majority of non-completers $(78.9 \%)$ did not have elevated Mollification scale scores $\left(\chi^{2}=5.142, \mathrm{df}=1, p<.05\right)$ and $71.9 \%$ did not have elevated Cognitive Indolence scale scores $\left(\chi^{2}=5.127, \mathrm{df}=1, p<.05\right)$. 
Table 1

Assessment Measures Utilized

\begin{tabular}{|c|c|c|c|c|}
\hline Measure & Scoring & Format & Reading Level & Time to Administer \\
\hline \multirow[t]{2}{*}{ GAMA } & $M=100$ & Stimulus Booklet & 2.5 grade & 25 min. (timed) \\
\hline & $(\mathrm{SD}=15)$ & Multiple-choice & & \\
\hline \multirow[t]{2}{*}{ PAI } & $\mathrm{T} \geq 70$ interpreted & Self-Report & 4 th grade & Approx. $45 \mathrm{~min}$. \\
\hline & & Likert-type & & \\
\hline \multirow[t]{2}{*}{ PDS } & Higher scores $=$ dishonest responding & Self-Report & $5^{\text {th }}$ grade & Approx. $10 \mathrm{~min}$. \\
\hline & & Likert-type & & \\
\hline \multirow[t]{2}{*}{ PICTS } & $\mathrm{T} \geq 60$ interpreted & Self-Report & $6^{\text {th }}$ grade & $15-30 \mathrm{~min}$. \\
\hline & & Likert-type & & \\
\hline
\end{tabular}

Note. GAMA = General Abilities Measure for Adults, PAI = Personality Assessment Inventory, PDS = Paulhus Deception Scale, PICTS $=$ Psychological Inventory of Criminal Thinking Styles. 
Table 2

Demographic Data for Total Sample

\begin{tabular}{|c|c|c|c|c|}
\hline & Mean & $S D$ & $N$ & Percentage \\
\hline Age & 36.15 & 9.87 & & \\
\hline Education & 12.09 & 2.13 & & \\
\hline GAMA & 97.44 & 12.57 & & \\
\hline Current Sentence (months) & 60.96 & 37.69 & & \\
\hline Total Time Served (months) & 36.61 & 35.09 & & \\
\hline Number of Incarcerations & 2.33 & 2.66 & & \\
\hline Number of Children & 1.95 & 1.80 & & \\
\hline Voluntary Outpatient & .59 & 1.67 & & \\
\hline Involuntary Outpatient & .45 & 1.77 & & \\
\hline Voluntary Inpatient & .33 & 1.01 & & \\
\hline Involuntary Inpatient & .26 & 1.93 & & \\
\hline Alcohol Use (years) & 15.94 & 10.06 & & \\
\hline Amphetamine Use (years) & 2.28 & 4.88 & & \\
\hline Cannabis Use (years) & 12.42 & 9.77 & & \\
\hline Cocaine Use (years) & 5.32 & 7.56 & & \\
\hline Hallucinogen Use (years) & 1.19 & 3.82 & & \\
\hline Inhalant Use (years) & .22 & 1.81 & & \\
\hline Opiate Use (years) & 1.43 & 4.12 & & \\
\hline PCP Use (years) & .46 & 1.88 & & \\
\hline Sedative/Hypnotics/Anxiolytic Use (years) & 1.36 & 4.15 & & \\
\hline Other Drug Use (years) & .44 & 1.62 & & \\
\hline
\end{tabular}




\begin{tabular}{|c|c|c|c|c|}
\hline & Mean & $S D$ & $N$ & Percentage \\
\hline \multicolumn{5}{|l|}{ Ethnicity } \\
\hline Caucasian & & & 88 & $34.6 \%$ \\
\hline African-American & & & 137 & $53.9 \%$ \\
\hline Hispanic-American & & & 19 & $7.5 \%$ \\
\hline Asian-American & & & 4 & $1.6 \%$ \\
\hline Native-American & & & 4 & $1.6 \%$ \\
\hline Other & & & 2 & $.8 \%$ \\
\hline \multicolumn{5}{|l|}{ Marital Status } \\
\hline Single & & & 130 & $51.2 \%$ \\
\hline Married/Common-Law & & & 78 & $30.7 \%$ \\
\hline Separated & & & 9 & $3.5 \%$ \\
\hline Divorced & & & 37 & $14.6 \%$ \\
\hline \multicolumn{5}{|l|}{ Current Offense } \\
\hline Drug & & & 226 & $89 \%$ \\
\hline Property & & & 3 & $1.2 \%$ \\
\hline Violation & & & 1 & $.4 \%$ \\
\hline Other & & & 24 & $9.4 \%$ \\
\hline \multicolumn{5}{|l|}{ History of Violence } \\
\hline Yes & & & 228 & $89.8 \%$ \\
\hline No & & & 26 & $10.2 \%$ \\
\hline
\end{tabular}


Table 3

Sociodemographic Variables by Completion Status

\begin{tabular}{|c|c|c|c|}
\hline Sociodemographics & Non-completers & Completers & $\chi^{2}$ \\
\hline & $n=82$ & $n=172$ & \\
\hline Age & & & 1.153 \\
\hline 35 and younger & $45(54.9 \%)$ & $82(47.7 \%)$ & \\
\hline Older than 35 & $37(45.1 \%)$ & $90(52.3 \%)$ & \\
\hline Education & & & .000 \\
\hline Less than 12 yrs & $61(74.4 \%)$ & $128(74.4 \%)$ & \\
\hline $12 \mathrm{yrs} / \mathrm{GED}$ or more & $21(25.6 \%)$ & $44(25.6 \%)$ & \\
\hline GAMA & & & 1.611 \\
\hline$<90$ & $16(19.5 \%)$ & $23(13.4 \%)$ & \\
\hline$\geq 90$ & $66(80.5 \%)$ & $149(84.6 \%)$ & \\
\hline Marital Status & & & .299 \\
\hline Married/Common-law & $24(29.3 \%)$ & $54(31.4 \%)$ & \\
\hline Separated $^{\mathrm{a}}$ & $3(3.7 \%)$ & $6(3.5 \%)$ & \\
\hline Divorced $^{\mathrm{a}}$ & $11(13.4 \%)$ & $26(15.1 \%)$ & \\
\hline Single & $44(53.7 \%)$ & $86(50 \%)$ & \\
\hline Number of Children & & & .264 \\
\hline 2 or less & $19(23.2 \%)$ & $45(26.2 \%)$ & \\
\hline More than 2 & $63(24.8 \%)$ & $127(73.8 \%)$ & \\
\hline
\end{tabular}







Treatment Completion 41

\begin{tabular}{|c|c|c|c|}
\hline Sociodemographics & $\begin{array}{l}\text { Non-completers } \\
\qquad n=82 \\
\end{array}$ & $\begin{array}{l}\text { Completers } \\
n=172 \\
\end{array}$ & $\chi^{2}$ \\
\hline Current Offense & & & 1.609 \\
\hline Drug & $70(85.4 \%)$ & $156(90.7 \%)$ & \\
\hline Property ${ }^{\mathrm{c}}$ & $0(0 \%)$ & $3(1.7 \%)$ & \\
\hline Supervised Release Violation ${ }^{c}$ & $0(0 \%)$ & $1(.6 \%)$ & \\
\hline Other ${ }^{\mathrm{c}}$ & $12(14.6 \%)$ & $12(7 \%)$ & \\
\hline Substance Abuse Treatment History & & & .529 \\
\hline No & $29(35.4 \%)$ & $69(40.1 \%)$ & \\
\hline Yes & $53(64.6 \%)$ & $103(59.9 \%)$ & \\
\hline Alcohol Use & & & $3.585^{*}$ \\
\hline Less than 1 year & $66(80.5 \%)$ & $119(69.2 \%)$ & \\
\hline 1 year or more & $16(19.5 \%)$ & $53(30.8 \%)$ & \\
\hline Amphetamine Use & & & $3.547^{*}$ \\
\hline Less than 1 year & $65(79.3 \%)$ & $117(68 \%)$ & \\
\hline 1 year or more & $17(20.7 \%)$ & $55(32 \%)$ & \\
\hline Cannabis Use & & & $4.554^{* *}$ \\
\hline Less than 1 year & $16(19.5 \%)$ & $17(9.9 \%)$ & \\
\hline 1 year or more & $66(80.5 \%)$ & $155(90.1 \%)$ & \\
\hline Cocaine Use & & & .181 \\
\hline Less than 1 year & $40(48.8 \%)$ & $79(45.9 \%)$ & \\
\hline 1 year or more & $42(51.2 \%)$ & $93(54.1 \%)$ & \\
\hline
\end{tabular}


Treatment Completion 42

\begin{tabular}{|c|c|c|c|}
\hline Sociodemographics & Non-completers & Completers & $x^{2}$ \\
\hline & $n=82$ & $n=172$ & \\
\hline Hallucinogens & & & .221 \\
\hline Less than 1 year & $66(80.5 \%)$ & $134(77.9 \%)$ & \\
\hline 1 year or more & $16(19.5 \%)$ & $38(22.1 \%)$ & \\
\hline Inhalants & & & .213 \\
\hline Less than 1 year & $76(92.7 \%)$ & $162(94.2 \%)$ & \\
\hline 1 year or more & $6(7.3 \%)$ & $10(5.8 \%)$ & \\
\hline Opiates & & & 1.347 \\
\hline Less than 1 year & $69(84.1 \%)$ & $134(77.9 \%)$ & \\
\hline 1 year or more & $13(15.9 \%)$ & $38(22.1 \%)$ & \\
\hline Phencyclidine & & & .030 \\
\hline Less than 1 year & $74(90.2 \%)$ & $154(89.5 \%)$ & \\
\hline 1 year or more & $8(9.8 \%)$ & $18(10.5 \%)$ & \\
\hline Sedatives/Hypnotics/Anxiolytics & & & .008 \\
\hline Less than 1 year & $63(76.8 \%)$ & $133(77.3 \%)$ & \\
\hline 1 year or more & $19(23.2 \%)$ & $39(22.7 \%)$ & \\
\hline Other Substances & & & .506 \\
\hline Less than 1 year & $72(87.8 \%)$ & $156(90.7 \%)$ & \\
\hline 1 year or more & $10(12.2 \%)$ & $16(9.3 \%)$ & \\
\hline
\end{tabular}

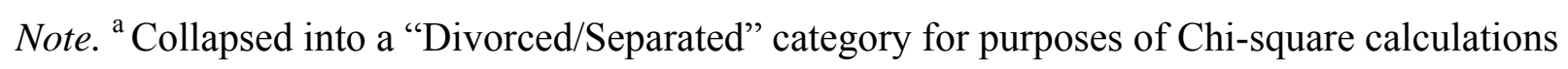
due to $\mathrm{N} \geq 5$ per cell. ${ }^{\mathrm{b}}$ Collapsed into "Other" category for purposes of Chi-square calculation 
due to $\mathrm{N} \geq 5$ per cell. ${ }^{\mathrm{c}}$ Collapsed into an "Other" category for purposes of Chi-square calculation due to $\mathrm{N} \geq 5$ per cell. GAMA $=$ General Abilities Measure for Adults. ${ }^{*} \mathrm{p}<.075 .{ }^{* *} \mathrm{p}<.05 .{ }^{* * *} \mathrm{p}<.001$. 
Table 4

Correlations among related variables

\begin{tabular}{|l|c|c|c|c|c|c|c|c|c|c|c|}
\hline & 2 & 3 & 4 & 5 & 6 & 7 & 8 & 9 & 10 & 11 & 12 \\
\hline 1) PAI-DRG & $.148^{*}$ & $.318^{* *}$ & .041 & .091 & .114 & $.153^{*}$ & $.136^{*}$ & $.179^{* *}$ & -.065 & $.124^{*}$ & .071 \\
\hline 2) PAI-ALC & & $.318^{* *}$ & .041 & .083 & $.222^{* *}$ & .114 & .100 & .080 & .085 & $.183^{*}$ & .100 \\
\hline 3) Alcohol & & & $.148^{*}$ & $.436^{*}$ & $.386^{*}$ & $.214^{* *}$ & .087 & .082 & .013 & $.249^{* *}$ & .059 \\
\hline 4) Amphetamine & & & & .103 & -.108 & $.143^{*}$ & $.123^{*}$ & -.016 & .074 & $.230^{*}$ & -.060 \\
\hline 5) Cannabis & & & & & $.384^{* *}$ & $.239^{*}$ & .081 & -.035 & $.136^{*}$ & $.264^{* *}$ & -.086 \\
\hline 6) Cocaine & & & & & & $.266^{* *}$ & $.147^{*}$ & $.171^{*}$ & .088 & $.200^{*}$ & -.055 \\
\hline 7) Hallucinogens & & & & & & & $.456^{* *}$ & $.181^{*}$ & $.177^{* *}$ & $.221^{* *}$ & .111 \\
\hline 8) Inhalants & & & & & & & & .025 & $.364^{* *}$ & $.271^{* *}$ & .014 \\
\hline 9) Opiates & & & & & & & & & -.042 & .071 & .058 \\
\hline 10) PCP & & & & & & & & & & & \\
\hline 11) Sedatives
\end{tabular}


Table 5

ANOVA results for Sociodemographic Data

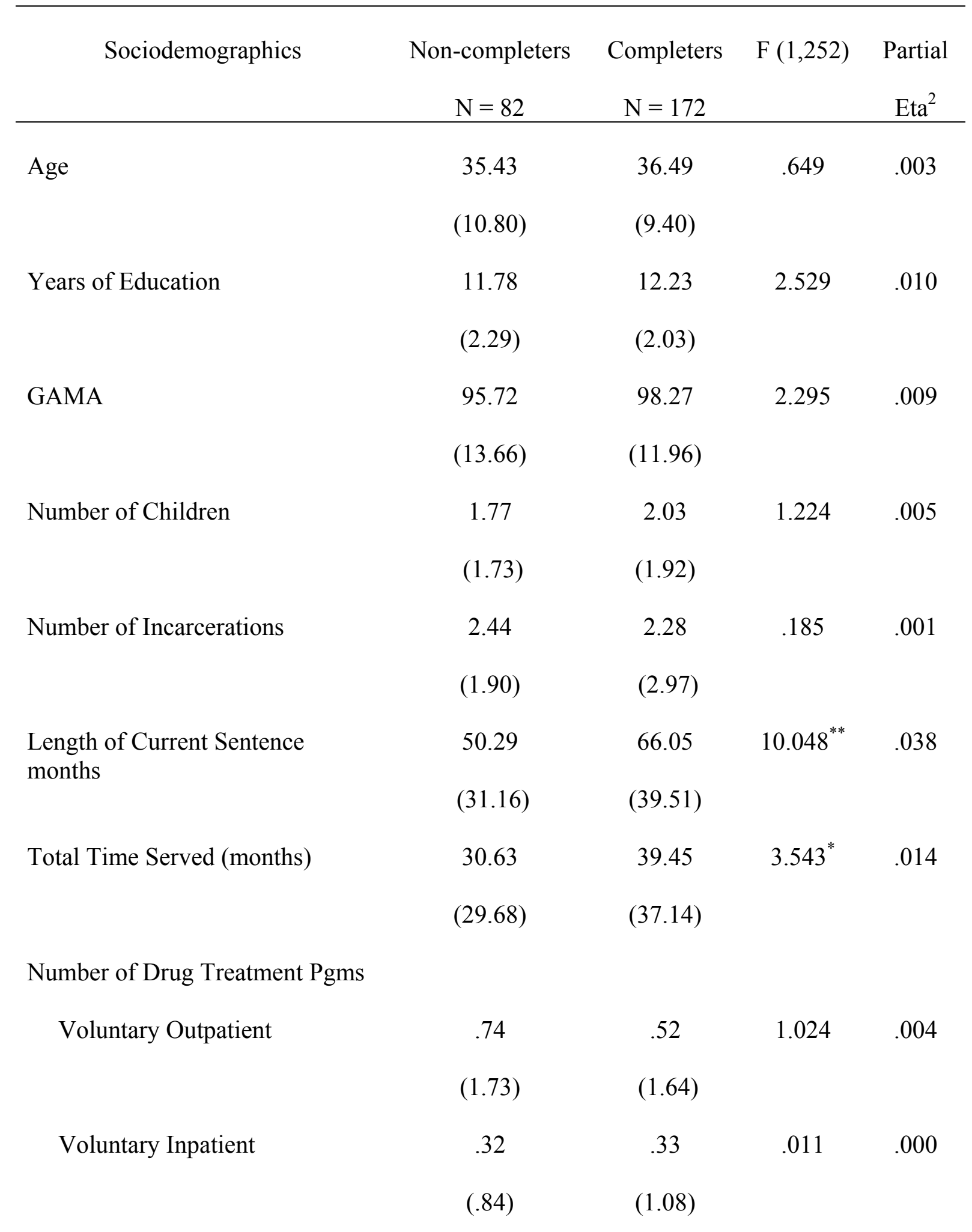




\begin{tabular}{|c|c|c|c|c|}
\hline \multirow[t]{2}{*}{ Sociodemographics } & Non-completers & Completers & $\mathrm{F}(1,252)$ & Partial \\
\hline & $\mathrm{N}=82$ & $\mathrm{~N}=172$ & & Eta $^{2}$ \\
\hline \multirow[t]{2}{*}{ Involuntary Outpatient } & .45 & .45 & .000 & .000 \\
\hline & $(1.43)$ & $(1.91)$ & & \\
\hline \multirow[t]{2}{*}{ Involuntary Inpatient } & .15 & .31 & .417 & .002 \\
\hline & $(.42)$ & (2.33) & & \\
\hline \multirow[t]{2}{*}{ Alcohol Use (years) } & 15.44 & 16.18 & .270 & .001 \\
\hline & (11.18) & $(10.43)$ & & \\
\hline \multirow[t]{2}{*}{ Amphetamine Use (years) } & 1.32 & 2.74 & $4.763^{* *}$ & .019 \\
\hline & $(3.62)$ & (5.33) & & \\
\hline \multirow[t]{2}{*}{ Cannabis Use (years) } & 11.57 & 12.82 & .902 & .004 \\
\hline & $(9.44)$ & $(9.94)$ & & \\
\hline \multirow[t]{2}{*}{ Cocaine Use (years) } & 5.13 & 5.40 & .071 & .000 \\
\hline & (7.00) & $(7.83)$ & & \\
\hline \multirow[t]{2}{*}{ Hallucinogen Use (years) } & 1.41 & 1.08 & .430 & .002 \\
\hline & $(4.18)$ & $(3.64)$ & & \\
\hline \multirow[t]{2}{*}{ Inhalant Use (years) } & .46 & .10 & 2.238 & .009 \\
\hline & $(3.05)$ & $(.61)$ & & \\
\hline \multirow[t]{2}{*}{ Opiate Use (years) } & 1.30 & 1.48 & .103 & .749 \\
\hline & $(3.87)$ & $(4.25)$ & & \\
\hline
\end{tabular}




\begin{tabular}{|c|c|c|c|c|}
\hline \multirow[t]{2}{*}{ Sociodemographics } & Non-completers & Completers & $F(1,252)$ & Partial \\
\hline & $\mathrm{N}=82$ & $\mathrm{~N}=172$ & & $\mathrm{Eta}^{2}$ \\
\hline \multirow[t]{2}{*}{ Phencyclidine Use (years) } & .50 & .44 & .058 & .000 \\
\hline & $(1.80)$ & $(1.92)$ & & \\
\hline \multirow{2}{*}{$\begin{array}{l}\text { Sedatives/Hypnotics/Anxiolytics } \\
\text { (years }\end{array}$} & 1.39 & 1.34 & .007 & .000 \\
\hline & $(3.30)$ & $(4.51)$ & & \\
\hline \multirow[t]{2}{*}{ Other Drug Use (years) } & .34 & .48 & .430 & .002 \\
\hline & $(1.18)$ & $(1.79)$ & & \\
\hline
\end{tabular}


Table 6

ANOVA results for all Validity Scales

\begin{tabular}{ccccc} 
Scale & Non-Completers & Completers & $F(1,252)$ & Partial Eta $^{2}$ \\
\hline PDS-Total & 8.76 & 7.90 & 1.649 & .007 \\
PAI INC & $(5.79)$ & $(4.57)$ & & .007 \\
PAI INF & 53.79 & 52.42 & 1.730 & .000 \\
& $(8.42)$ & $(7.46)$ & & .040 \\
PAI NIM & 55.27 & 55.02 & & .000 \\
& $(9.18)$ & $(9.16)$ & .018 & .006 \\
PAI PIM & 55.76 & 55.97 & & \\
& $(10.52)$ & $(12.05)$ & 1.539 & .002 \\
PICTS Cf-r & 43.99 & 42.21 & & .006 \\
& $(10.73)$ & $(10.66)$ & & \\
PICTS Df-r & 55.49 & 54.85 & & \\
& $(10.41)$ & $(9.89)$ & & \\
\hline
\end{tabular}

Note. PDS-Total $=$ Paulhus Deception Scale - Total score; PAI $=$ Personality Assessment Inventory; INC = Inconsistency; INF = Infrequency; NIM = Negative Impression Management; PIM = Positive Impression Management. PICTS = Psychological Inventory of Criminal Thinking Styles; Cf-r = Confusion-Revised; Df-r = Defensiveness-Revised; Discrepancies in $N$ reflect lack of data for all participants. Results not significant at $\mathrm{p}<.05$. 
Table 7

Clinically Elevated Validity Scale Chi-Square Analyses

\begin{tabular}{lcc} 
Scale & Non-Completers & Completers \\
\hline PAI INC & & \\
$<70$ & $77(93.9 \%)$ & $168(97.7 \%)$ \\
$\geq 70$ & $5(6.1 \%)$ & $4(2.3 \%)$
\end{tabular}

PAI INF

.180

$\begin{array}{lcc}<70 & 77(93.9 \%) & 159(92.4 \%) \\ \geq 70 & 5(6.1 \%) & 13(7.6 \%)\end{array}$

PAI NIM

.256

$<70$

$72(87.8 \%)$

$147(85.5 \%)$

$\geq 70$

$10(12.2 \%)$

$25(14.5 \%)$

PAI PIM
$<70$
$82(100 \%)$
$171(99.4 \%)$
$\geq 70$
$0(0 \%)$
$1(.6 \%)$

PICTS Cf-r

.384
$<70$
$60(73.2 \%)$
$132(76.7 \%)$
$\geq 70$
$22(26.8 \%)$
$40(23.3 \%)$

PICTS Df-r
$<70$
$79(96.3 \%)$
$169(98.3 \%)$
$\geq 70$
$3(3.7 \%)$
$3(1.7 \%)$

Note. $\mathrm{PAI}=$ Personality Assessment Inventory; $\mathrm{INC}=$ Inconsistency; INF = Infrequency; $\mathrm{NIM}=$ 
Negative Impression Management; PIM = Positive Impression Management. PICTS = Psychological Inventory of Criminal Thinking Styles; Cf-r = Confusion-Revised; Df-r = Defensiveness-Revised. Results not significant at $\mathrm{p}<.075$. 
Table 8

PAI Clinical, Treatment, and Interpersonal Subscale Main Effects

\begin{tabular}{|c|c|c|c|c|}
\hline $\begin{array}{c}\text { PAI } \\
\text { Scales }\end{array}$ & Non-Completers & Completers & $F(1,252)$ & Partial Eta ${ }^{2}$ \\
\hline SOM & $\begin{array}{c}54.37 \\
(11.78)\end{array}$ & $\begin{array}{r}53.56 \\
(10.30)\end{array}$ & .578 & .001 \\
\hline ANX & $\begin{array}{l}55.66 \\
(9.45)\end{array}$ & $\begin{array}{c}56.05 \\
(10.60)\end{array}$ & .082 & .000 \\
\hline ARD & $\begin{array}{l}59.65 \\
(9.50)\end{array}$ & $\begin{array}{c}58.32 \\
(10.46)\end{array}$ & .947 & .004 \\
\hline DEP & $\begin{array}{l}55.90 \\
(8.60)\end{array}$ & $\begin{array}{l}55.63 \\
(9.17)\end{array}$ & .052 & .000 \\
\hline MAN & $\begin{array}{r}55.89 \\
(11.49)\end{array}$ & $\begin{array}{r}53.76 \\
(10.62)\end{array}$ & 2.115 & .008 \\
\hline PAR & $\begin{array}{r}61.39 \\
(11.88)\end{array}$ & $\begin{array}{r}62.08 \\
(10.22)\end{array}$ & .228 & .001 \\
\hline $\mathrm{SCZ}$ & $\begin{array}{c}56.51 \\
(11.20)\end{array}$ & $\begin{array}{c}56.77 \\
(10.85)\end{array}$ & .030 & .000 \\
\hline BORD & $\begin{array}{l}63.45 \\
(9.77)\end{array}$ & $\begin{array}{c}63.69 \\
(10.35)\end{array}$ & .038 & .000 \\
\hline ANT & $\begin{array}{c}65.82 \\
(11.88)\end{array}$ & $\begin{array}{c}65.98 \\
(11.35)\end{array}$ & .011 & .000 \\
\hline
\end{tabular}




\begin{tabular}{|c|c|c|c|c|}
\hline $\begin{array}{c}\text { PAI } \\
\text { Scales }\end{array}$ & Non-Completers & Completers & $F(1,252)$ & Partial Eta ${ }^{2}$ \\
\hline ALC & $\begin{array}{c}68.89 \\
(16.49)\end{array}$ & $\begin{array}{c}72.38 \\
(16.87)\end{array}$ & 2.408 & .122 \\
\hline DRG & $\begin{array}{c}78.83 \\
(16.07)\end{array}$ & $\begin{array}{c}84.31 \\
(16.23)\end{array}$ & $6.363^{* *}$ & .025 \\
\hline AGG & $\begin{array}{c}56.98 \\
(12.04)\end{array}$ & $\begin{array}{c}56.60 \\
(11.84)\end{array}$ & .054 & .000 \\
\hline SUI & $\begin{array}{l}49.07 \\
(7.38)\end{array}$ & $\begin{array}{l}48.40 \\
(7.90)\end{array}$ & .419 & .002 \\
\hline STR & $\begin{array}{c}60.17 \\
(11.22)\end{array}$ & $\begin{array}{c}61.05 \\
(10.66)\end{array}$ & .362 & .001 \\
\hline $\mathrm{NON}$ & $\begin{array}{c}53.94 \\
(10.15)\end{array}$ & $\begin{array}{c}56.60 \\
(10.15)\end{array}$ & 3.811 & .015 \\
\hline RXR & $\begin{array}{l}34.77 \\
(8.24)\end{array}$ & $\begin{array}{r}34.56 \\
(8.46)\end{array}$ & .035 & .000 \\
\hline
\end{tabular}

Note. $\mathrm{PAI}=$ Personality Assessment Inventory; $\mathrm{SOM}=$ Somatic Complaints ANX = Anxiety; $\mathrm{ARD}=$ Anxiety Related Disorders; $\mathrm{DEP}=$ Depression; $\mathrm{MAN}=$ Mania; $\mathrm{PAR}=$ Paranoia; $\mathrm{SCZ}=$ Schizophrenia BORD $=$ Borderline Features $;$ ANT $=$ Antisocial Features $;$ ALC $=$ Alcohol Problems; $\mathrm{DRG}=$ Drug Problems; $\mathrm{AGG}=$ Aggression $; \mathrm{SUI}=$ Suicidal Ideation; $\mathrm{STR}=$ Stress; $\mathrm{NON}=$ Nonsupport; $\mathrm{RXR}=$ Treatment Rejection. All reported scores are T-Scores. ${ }^{* *} \mathrm{p}<.05$. 
Table 9

PAI Clinical, Treatment, and Interpersonal Subscale Chi-Square Analyses

\begin{tabular}{|c|c|c|c|}
\hline PAI & Non-Completers & Completers & $\chi^{2}$ \\
\hline Scales & $n=72$ & $n=182$ & \\
\hline SOM & & & .013 \\
\hline$<70$ & $74(90.2 \%)$ & $156(90.7 \%)$ & \\
\hline$\geq 70$ & $8(9.8 \%)$ & $16(9.3 \%)$ & \\
\hline ANX & & & .444 \\
\hline$<70$ & $76(92.7 \%)$ & $155(90.1 \%)$ & \\
\hline$\geq 70$ & $6(7.3 \%)$ & $17(9.9 \%)$ & \\
\hline ARD & & & 2.380 \\
\hline$<70$ & $66(80.5 \%)$ & $151(87.8 \%)$ & \\
\hline$\geq 70$ & $16(19.5 \%)$ & $21(12.2 \%)$ & \\
\hline DEP & & & .354 \\
\hline$<70$ & $74(90.2 \%)$ & $159(92.4 \%)$ & \\
\hline$\geq 70$ & $8(9.8 \%)$ & $13(7.6 \%)$ & \\
\hline MAN & & & 2.549 \\
\hline$<70$ & $70(85.4 \%)$ & $158(91.9 \%)$ & \\
\hline$\geq 70$ & $12(14.6 \%)$ & $14(8.1 \%)$ & \\
\hline PAR & & & .017 \\
\hline$<70$ & $64(78 \%)$ & $133(77.3 \%)$ & \\
\hline$\geq 70$ & $18(22 \%)$ & $39(22.7 \%)$ & \\
\hline
\end{tabular}


Treatment Completion 54

\begin{tabular}{|c|c|c|c|}
\hline PAI & Non-Completers & Completers & $\chi^{2}$ \\
\hline Scales & $n=72$ & $n=182$ & \\
\hline $\mathrm{SCZ}$ & & & .072 \\
\hline$<70$ & $72(87.8 \%)$ & $153(89 \%)$ & \\
\hline$\geq 70$ & $10(12.2 \%)$ & $19(11 \%)$ & \\
\hline BORD & & & .007 \\
\hline$<70$ & $60(73.2 \%)$ & $125(72.7 \%)$ & \\
\hline$\geq 70$ & $22(26.8 \%)$ & $47(27.3 \%)$ & \\
\hline ANT & & & 2.486 \\
\hline$<70$ & $48(58.5 \%)$ & $118(68.6 \%)$ & \\
\hline$\geq 70$ & $34(41.5 \%)$ & $54(31.4 \%)$ & \\
\hline ALC & & & 2.041 \\
\hline$<70$ & $46(56.1 \%)$ & $80(46.5 \%)$ & \\
\hline$\geq 70$ & $36(43.9 \%)$ & $92(53.5 \%)$ & \\
\hline DRG & & & $9.071^{* *}$ \\
\hline$<70$ & $27(32.9 \%)$ & $28(16.3 \%)$ & \\
\hline$\geq 70$ & $55(67.1 \%)$ & $144(83.7 \%)$ & \\
\hline $\mathrm{AGG}$ & & & .148 \\
\hline$<70$ & $72(87.8 \%)$ & $148(86 \%)$ & \\
\hline$\geq 70$ & $10(12.2 \%)$ & $24(14 \%)$ & \\
\hline
\end{tabular}




\begin{tabular}{cccc}
\hline PAI & Non-Completers & Completers & $\chi^{2}$ \\
Scales & $n=72$ & $n=182$ & - \\
\hline SUI & & & \\
$<70$ & $81(98.8 \%)$ & $165(95.9 \%)$ & .264 \\
$\geq 70$ & $1(1.2 \%)$ & $7(4.1 \%)$ & \\
STR & & $135(78.5 \%)$ & -- \\
$<70$ & $62(75.6 \%)$ & $37(21.5 \%)$ & \\
$\geq 70$ & $20(24.4 \%)$ & $163(94.8 \%)$ & - \\
NON & & $9(5.2 \%)$ & \\
$<70$ & $78(95.1 \%)$ & $171(99.4 \%)$ & \\
RXR & $4(4.9 \%)$ & $1(.6 \%)$ & \\
$<70$ & & & \\
$\geq 70$ & $02(100 \%)$ & & \\
\hline
\end{tabular}

Note. $\mathrm{PAI}=$ Personality Assessment Inventory; $\mathrm{SOM}=$ Somatic Complaints ANX = Anxiety; $\mathrm{ARD}=$ Anxiety Related Disorders; $\mathrm{DEP}=$ Depression; $\mathrm{MAN}=$ Mania; $\mathrm{PAR}=$ Paranoia; $\mathrm{SCZ}=$ Schizophrenia BORD $=$ Borderline Features ANT $=$ Antisocial Features $;$ ALC $=$ Alcohol Problems; DRG= Drug Problems; $\mathrm{AGG}=$ Aggression; $\mathrm{SUI}=$ Suicidal Ideation; $\mathrm{STR}=$ Stress; NON $=$ Nonsupport; RXR $=$ Treatment Rejection. Chi-square analyses for SUI, NON, and RXR could not be calculated due to cell count $<5$. ${ }^{* *} \mathrm{p}<.05$. 
Table 10

ANOVA results for PICTS

\begin{tabular}{|c|c|c|c|c|}
\hline $\begin{array}{l}\text { PICTS } \\
\text { Scales }\end{array}$ & Non-Completers & Completers & $F(1,252)$ & Partial Eta ${ }^{2}$ \\
\hline Mo & $\begin{array}{c}55.91 \\
(11.99\end{array}$ & $\begin{array}{c}57.90 \\
(12.67)\end{array}$ & 1.411 & .006 \\
\hline Co & $\begin{array}{c}58.71 \\
(10.17)\end{array}$ & $\begin{array}{l}59.35 \\
(9.43)\end{array}$ & .244 & .001 \\
\hline En & $\begin{array}{c}57.13 \\
(10.81)\end{array}$ & $\begin{array}{c}56.51 \\
(10.29)\end{array}$ & .200 & .001 \\
\hline Po & $\begin{array}{c}57.80 \\
(11.63)\end{array}$ & $\begin{array}{c}56.28 \\
(11.15)\end{array}$ & 1.004 & .004 \\
\hline $\mathrm{Sn}$ & $\begin{array}{c}52.95 \\
(11.82)\end{array}$ & $\begin{array}{l}52.87 \\
(9.57)\end{array}$ & .003 & .000 \\
\hline So & $\begin{array}{c}62.91 \\
(12.78)\end{array}$ & $\begin{array}{c}62.16 \\
(11.47)\end{array}$ & .221 & .001 \\
\hline $\mathrm{Ci}$ & $\begin{array}{l}58.24 \\
(9.52)\end{array}$ & $\begin{array}{l}59.27 \\
(9.42)\end{array}$ & .652 & .003 \\
\hline Ds & $\begin{array}{c}57.15 \\
(10.66)\end{array}$ & $\begin{array}{l}58.35 \\
(9.80)\end{array}$ & .797 & .003 \\
\hline CUR & $\begin{array}{l}57.62 \\
(9.71)\end{array}$ & $\begin{array}{l}58.51 \\
(9.87)\end{array}$ & .450 & .002 \\
\hline
\end{tabular}




\begin{tabular}{ccccc}
\hline PICTS & Non-Completers & Completers & $F(1,252)$ & Partial Eta $^{2}$ \\
Scales & & & & \\
\hline HIS & 62.06 & 63.85 & 1.538 & .006 \\
& $(11.43)$ & $(10.41)$ & & .003 \\
PRB & 58.13 & 59.34 & .854 & \\
& $(9.72)$ & $(9.69)$ & & .000 \\
HOS & 52.76 & 52.98 & .023 & .001 \\
& $(11.02)$ & $(11.19)$ & & .004 \\
AST & 61.49 & 62.08 & .164 & \\
& $(11.00)$ & $(10.71)$ & & .004 \\
DNH & 52.06 & 50.80 & .931 & \\
& $(10.21)$ & $(9.48)$ & & .959 \\
FOC & 60.13 & 61.57 & $(10.91)$ & \\
\hline
\end{tabular}

Note. PICTS $=$ Psychological Inventory of Criminal Thinking Styles; $\mathrm{Mo}=$ Mollification $; \mathrm{Co}=$ Cut-Off; En = Entitlement; Po = Power Orientation; Sn = Sentimentality; So = Superoptimism; $\mathrm{Ci}=$ Cognitive Indolence; Ds = Discontinuity; CUR = Current; HIS = Historical; PRB = Problem Avoidance; HOS = Interpersonal Hostility; AST = Self-Assertion; DNH = Denial of Harm; FOC $=$ Fear of Change. All reported scores are T-Scores.

Results not significant at $\mathrm{p}<.05$. 
Table 11

PICTS Chi-Square Analyses

\begin{tabular}{|c|c|c|c|}
\hline PICTS & Non-Completers & Completers & $\chi^{2}$ \\
\hline Scales & $n=72$ & $n=182$ & \\
\hline Mo & & & 2.583 \\
\hline$<60$ & $54(65.9 \%)$ & $95(55.2 \%)$ & \\
\hline$\geq 60$ & $28(34.1 \%)$ & $77(44.5 \%)$ & \\
\hline $\mathrm{Co}$ & & & 1.519 \\
\hline$<60$ & $43(52.4 \%)$ & $76(44.2 \%)$ & \\
\hline$\geq 60$ & $39(47.6 \%)$ & $96(55.8 \%)$ & \\
\hline En & & & 2.189 \\
\hline$<60$ & $47(57.3 \%)$ & $115(66.9 \%)$ & \\
\hline$\geq 60$ & $35(42.7 \%)$ & $57(33.1 \%)$ & \\
\hline Po & & & .557 \\
\hline$<60$ & $47(57.3 \%)$ & $107(62.2 \%)$ & \\
\hline$\geq 60$ & $35(42.7 \%)$ & $65(37.8 \%)$ & \\
\hline $\mathrm{Sn}$ & & & .000 \\
\hline$<60$ & $60(73.2 \%)$ & $126(73.3 \%)$ & \\
\hline$\geq 60$ & $22(26.8 \%)$ & $46(26.7 \%)$ & \\
\hline So & & & .454 \\
\hline$<60$ & $38(46.3 \%)$ & $72(41.9 \%)$ & \\
\hline$\geq 60$ & $44(53.7 \%)$ & $100(58.1 \%)$ & \\
\hline
\end{tabular}




\begin{tabular}{|c|c|c|c|}
\hline PICTS & Non-Completers & Completers & $\chi^{2}$ \\
\hline Scales & $n=72$ & $n=182$ & \\
\hline $\mathrm{Ci}$ & & & 2.019 \\
\hline$<60$ & $45(54.9 \%)$ & 78 (45.3\%) & \\
\hline$\geq 60$ & $37(45.1 \%)$ & $94(54.7 \%)$ & \\
\hline Ds & & & .025 \\
\hline$<60$ & $43(52.4 \%)$ & $92(53.5 \%)$ & \\
\hline$\geq 60$ & $39(47.6 \%)$ & $80(46.5 \%)$ & \\
\hline CUR & & & .482 \\
\hline$<60$ & $41(50 \%)$ & $94(54.7 \%)$ & \\
\hline$\geq 60$ & $41(50 \%)$ & $78(45.3 \%)$ & \\
\hline HIS & & & $4.622^{* *}$ \\
\hline$<60$ & $35(42.7 \%)$ & $50(29.1 \%)$ & \\
\hline$\geq 60$ & $47(57.3 \%)$ & $122(70.9 \%)$ & \\
\hline PRB & & & .693 \\
\hline$<60$ & $47(57.3 \%)$ & $89(51.7 \%)$ & \\
\hline$\geq 60$ & $35(42.7 \%)$ & $83(48.3 \%)$ & \\
\hline HOS & & & .888 \\
\hline$<60$ & $65(79.3 \%)$ & $127(73.8 \%)$ & \\
\hline$\geq 60$ & $17(20.7 \%)$ & $45(26.2 \%)$ & \\
\hline
\end{tabular}




\begin{tabular}{cccc}
\hline PICTS & Non-Completers & Completers & $\chi^{2}$ \\
Scales & $n=72$ & $n=182$ & .007 \\
\hline AST & & & \\
$<60$ & $30(36.6 \%)$ & $62(36 \%)$ & \\
$\geq 60$ & $52(63.4 \%)$ & $110(64 \%)$ & .003 \\
DNH & & & \\
$<60$ & $67(81.7 \%)$ & $141(82 \%)$ & .572 \\
$\geq 60$ & $15(18.3 \%)$ & $31(18 \%)$ & \\
FOC & & & \\
$<60$ & $37(45.1 \%)$ & $69(40.1 \%)$ & \\
$\geq 60$ & $45(54.9 \%)$ & $103(59.9 \%)$ & \\
\hline
\end{tabular}

Note. PICTS $=$ Psychological Inventory of Criminal Thinking Styles; $\mathrm{Mo}=$ Mollification; $\mathrm{Co}=$ Cut-Off; En = Entitlement; Po = Power Orientation; $\mathrm{Sn}=$ Sentimentality; So = Superoptimism; $\mathrm{Ci}=$ Cognitive Indolence; Ds = Discontinuity CUR = Current; HIS = Historical; PRB = Problem Avoidance $; \mathrm{HOS}=$ Interpersonal Hostility; AST = Self-Assertion; DNH = Denial of Harm; FOC $=$ Fear of Change.

$\stackrel{* *}{\mathrm{p}}<.05$. 
Table 12

Logistic Regression Analyses for Prediction of Completers

\begin{tabular}{|c|c|c|c|c|c|c|c|c|}
\hline & \multicolumn{4}{|c|}{$n=199$} & \multicolumn{4}{|c|}{$n=55$} \\
\hline & $\begin{array}{l}\text { Parameter } \\
\text { Estimate }\end{array}$ & SE & Wald $\chi^{2}$ & $\begin{array}{l}\text { Odds } \\
\text { Ratio }\end{array}$ & $\begin{array}{l}\text { Parameter } \\
\text { Estimate }\end{array}$ & SE & Wald $\chi^{2}$ & $\begin{array}{l}\text { Odds } \\
\text { Ratio }\end{array}$ \\
\hline $\begin{array}{l}\text { Current Sentence } \\
(\leq \text { or }>49 \text { months })\end{array}$ & .814 & .363 & $5.021^{* *}$ & 2.256 & .924 & .578 & 2.551 & 2.519 \\
\hline $\begin{array}{l}\# \text { of Incarcerations } \\
(\leq \text { or }>2)\end{array}$ & -.642 & .354 & 3.299 & .526 & & & & \\
\hline $\begin{array}{l}\text { Alcohol Use } \\
(<\text { or } \geq 1 \text { year })\end{array}$ & -.114 & 1.844 & .004 & .892 & & & & \\
\hline $\begin{array}{l}\text { Amphetamine Use } \\
(<\text { or } \geq 1 \text { year })\end{array}$ & 1.175 & 1.842 & .407 & 3.237 & & & & \\
\hline $\begin{array}{l}\text { Cannabis Use } \\
(<\text { or } \geq 1 \text { year })\end{array}$ & .638 & .488 & 1.705 & 1.892 & & & & \\
\hline
\end{tabular}




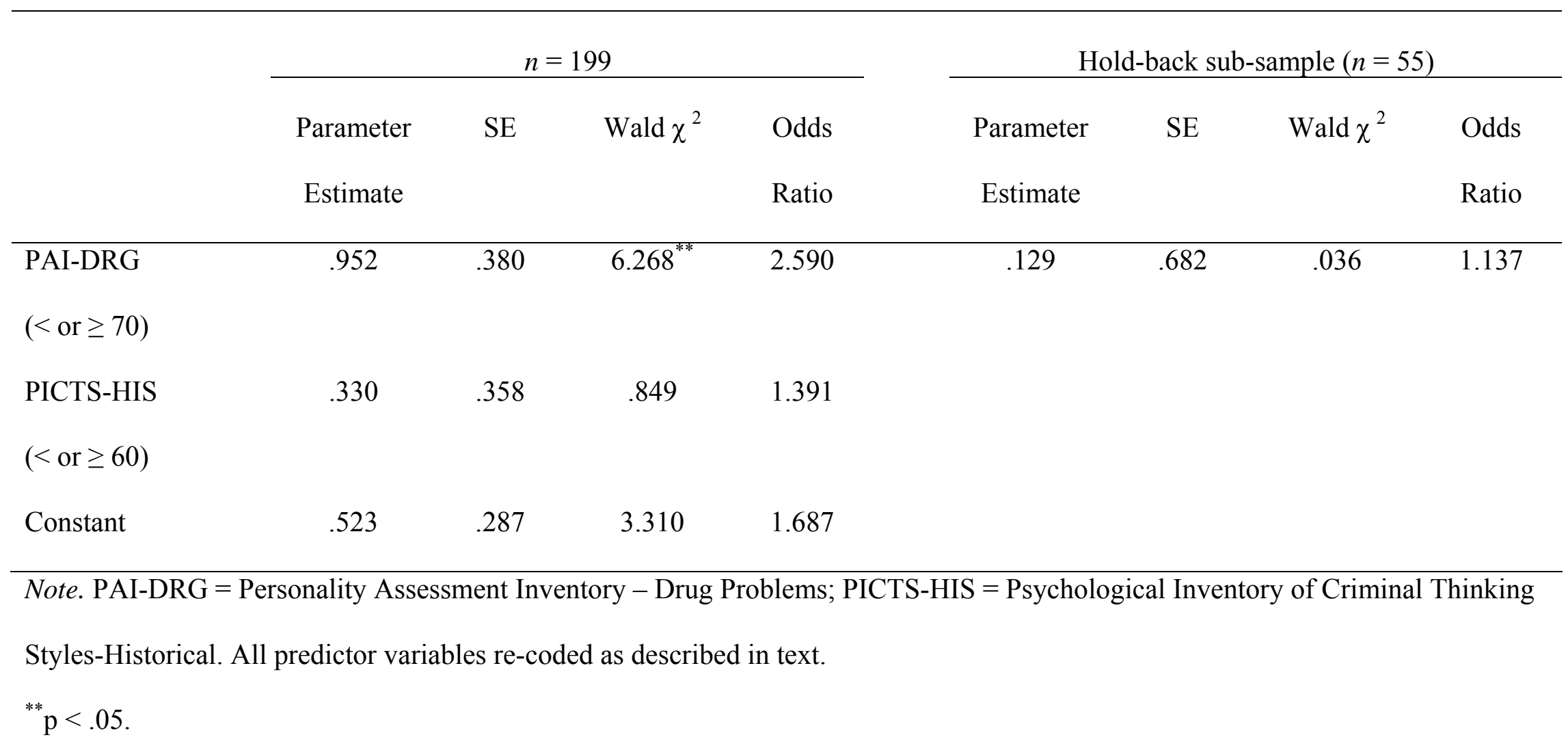


Table 13

Logistic Regression Classification Table

\begin{tabular}{|c|c|c|c|}
\hline & \multicolumn{2}{|c|}{ Predicted Group } & \multirow[b]{2}{*}{ Total } \\
\hline & Completers & Non-Completers & \\
\hline \multirow[t]{2}{*}{ Actual Completers } & 124 & 14 & 138 \\
\hline & $(89.9 \%)^{\mathrm{a}}$ & $(10.1 \%)$ & $(100 \%)$ \\
\hline \multirow[t]{2}{*}{ Actual Non-completers } & 41 & 20 & 61 \\
\hline & $(67.21 \%)$ & $(32.8 \%)^{b}$ & $(100 \%)$ \\
\hline
\end{tabular}

Note. ${ }^{\mathrm{a}}$ Sensitivity. ${ }^{\mathrm{b}}$ Specificity. 
Table 14

Discriminant Function Analysis Classification Table

\begin{tabular}{lccc}
\hline & \multicolumn{2}{c}{ Predicted Group Membership } & \\
\cline { 2 - 3 } & Completers & Non-Completers & Total \\
\hline Completers & 129 & 9 & 138 \\
Non-Completers & $(93.5 \%)^{\mathrm{a}}$ & $(6.5 \%)$ & $(100 \%)$ \\
& 46 & 15 & 61 \\
& $(75.4 \%)$ & $(24.6 \%)^{\mathrm{a}}$ & $(100 \%)$ \\
\hline
\end{tabular}

Note. ${ }^{\mathrm{a}}$ Conditional hit-rate calculated at $72.4 \%$. 